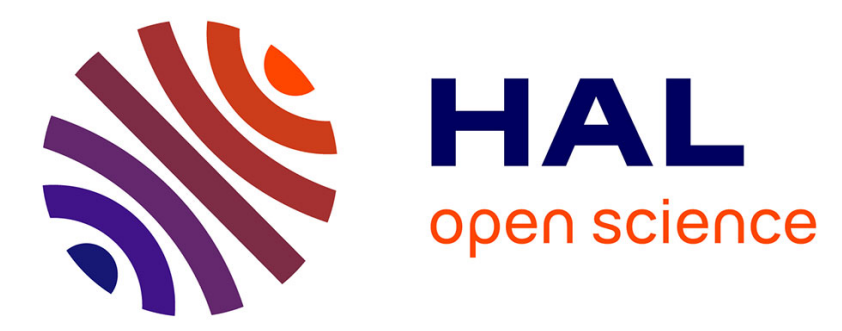

\title{
Systemic design and energy management of a standalone battery-less PV/Wind driven brackish water reverse osmosis desalination system
}

\author{
I. Ben Ali, M. Turki, J. Belhadj, Xavier Roboam
}

\section{To cite this version:}

I. Ben Ali, M. Turki, J. Belhadj, Xavier Roboam. Systemic design and energy management of a standalone battery-less PV/Wind driven brackish water reverse osmosis desalination system. Sustainable Energy Technologies and Assessments, 2020, 42, pp.100884. 10.1016/j.seta.2020.100884 . hal-02981480

\section{HAL Id: hal-02981480 \\ https://hal.science/hal-02981480}

Submitted on 20 Nov 2020

HAL is a multi-disciplinary open access archive for the deposit and dissemination of scientific research documents, whether they are published or not. The documents may come from teaching and research institutions in France or abroad, or from public or private research centers.
L'archive ouverte pluridisciplinaire HAL, est destinée au dépôt et à la diffusion de documents scientifiques de niveau recherche, publiés ou non, émanant des établissements d'enseignement et de recherche français ou étrangers, des laboratoires publics ou privés. 


\title{
Systemic Design and Energy Management of a Standalone Battery-less
} PV/Wind driven Brackish Water Reverse Osmosis Desalination System

\author{
I. Ben Ali ${ }^{\text {a, }}$ M. Turki ${ }^{\text {a, b }}$, J. Belhadj a, c, X. Roboam ${ }^{\text {d }}$ \\ ${ }^{a}$ Université de Tunis El Manar, LR 11 ES 15, Laboratoire des Systèmes Électriques, École Nationale d'Ingénieurs de Tunis, BP 37 - 1002, \\ Tunis le Belvédère, Tunis, Tunisia. \\ e-mail: ines.benali@enit.utm.tn \\ ${ }^{\text {b } U n i v e r s i t e ́ ~ d e ~ J e n d o u b a, ~ E ́ c o l e ~ S u p e ́ r i e u r e ~ d e s ~ I n g e ́ n i e u r s ~ d e ~ M e d j e z ~ E l ~ B a b, ~ P 5, ~ 9070, ~ T u n i s i a . ~}$ \\ e-mail: mehdi_turki1@yahoo.fr \\ ${ }^{\mathrm{c}}$ Université de Tunis, École Nationale Supérieure d'Ingénieurs de Tunis, BP 56 - 1008, Montfleury, Tunisia. \\ e-mail: Jamel.Belhadj@esstt.rnu.tn \\ ${ }^{\mathrm{d}}$ Université de Toulouse, LAPLACE (Laboratoire Plasma et Conversion d'Énergie), UMR CNRS-INP-UPS, ENSEEIHT, 2 Rue Camichel \\ 31071 Toulouse, France. \\ e-mail: Xavier.Roboam@laplace.univ-tlse.fr
}

\section{Abstract}

This work investigates a small-scale reverse osmosis desalination system dedicated for off-grid communities lacking freshwater. This system, constituted of motor-pumps, desalination process and hydraulic network (pipes and valves), is powered by hybrid photovoltaic-wind turbine source. It exploits hydraulic storage in water tanks filled when renewable energy is available instead of electrochemical storage. Such specificity makes the power/freshwater supply a challenging issue for these communities. To maximize freshwater production of this autonomous system, a "systemic design approach" integrating couplings between architecture, sizing, and energy management is proposed. According to the specific system architecture and its component sizing, a specific quasi-static model-based energy management strategy (EMS) is developed. In this regard, the influence of the main component sizing on the system energy efficiency and the EMS performance is analyzed. This study proved the strongly coupling between power/water management and pump sizing. According to the iterative process of the systemic design approach, simulation results showed that the EMS objective is reached by increasing the brackish water storage tank capacity and improving the system energy efficiency. The latter is achieved by choosing the pumps-combination composed of three pumps having the lowest rated powers $(0.37 \mathrm{~kW} / 0.37 \mathrm{~kW} / 1.5 \mathrm{~kW})$, but offering higher energy efficiency over other analyzed pumps-combinations.

Keywords: systemic design; electrochemical and water storage; quasi-static modeling; water/power management; renewable energy.

\section{Introduction}

Reverse osmosis (RO) desalination applications have been becoming the primary choice to produce freshwater from brackish or sea water for many water-stressed regions [1-2] not only for drinking, but also for agriculture [3]. Typically, these applications, especially small-scale units for off-grid communities, are powered by renewable energies [4-6]. The most commonly used renewable energies to power such desalination units are the solar energy [7-8] and the wind energy [9-10]. For example, according to the comprehensive review and the techno-economic feasibility carried out, respectively, in [11] and [8], photovoltaic PV-RO desalination systems are considered better than other desalination combinations due to their availability in the market and economic feasibility; this has encouraged poor farmers in rural regions to use these systems to produce freshwater. Another technoeconomic analysis of several wind-driven variable flow RO systems in United Arab Emirates was conducted [9]. 
41 This analysis concluded that Wind-RO combination is an economic alternative to produce freshwater. However, 42 although wind and solar energies are the most widespread and environmentally friendly Renewable Energy 43 Sources (RESs) worldwide, both are of variable and intermittent nature due to unpredictable and rough changes in 44 weather conditions (e.g. simultaneous cloudy sky or wind speed slowing down). For that, using single RES cannot 45 always meet the electrical demand of the RO plant during the day [12].

46 Hybrid power generation systems, such as solar PV panels combined with wind turbine [10], are becoming more 47 suitable with the advantage that one RES could be available when the other is not [6]. Such a temporal 48 complementarity will increase the reliability and improve the environmental aspect of the desalination system 49 [12]. On the other hand, standalone RO systems can be powered by different combinations of renewable energy 50 sources (e.g. PV-RO, Wind-RO and PV/Wind-RO) with one or more energy storage device, such as batteries [10], 51 super capacitors [13], fuel cell [14-15], and diesel generator backup [16]. A summary of different studied 52 standalone small-scale RES-brackish water RO units in different sites around the world is reported in Table1.

53 Table 1 Summarry of the reported standalone small-scale RES-BWRO units $\left(\leq 10 \mathrm{~m}^{3} / \mathrm{d}\right)$ in the last decade

\begin{tabular}{|c|c|c|c|c|c|c|c|c|c|}
\hline Ref. & Year & Country & PV (kW) & Wind (kW) & Battery & $\begin{array}{l}\begin{array}{l}\text { Diesel } \\
(\mathrm{kW})\end{array} \\
\end{array}$ & Hydrogen & $\begin{array}{l}\text { Freshwater } \\
(\mathrm{m} 3 / \mathrm{d})\end{array}$ & $\begin{array}{l}\text { Energy } \\
\text { Recovery (\%) }\end{array}$ \\
\hline [17] & 2010 & Spain & 0.36 & no & yes & no & no & $0.2(12 \mathrm{~h})$ & no \\
\hline$[18]$ & 2010 & Uzbekistan & 0.03 & no & yes & no & no & $0.075(9.5 \mathrm{~h})$ & no \\
\hline [19] & 2010 & Babylon, Iraq & 4.1 & no & yes & 1.8 & no & $5(24 h)$ & no \\
\hline [19] & 2010 & Babylon, Iraq & 1.6 & no & yes & 1 & no & $5(6 h)$ & no \\
\hline$[20]$ & 2011 & Australia & not mentioned & no & no & no & no & $4.8(12 h)$ & no \\
\hline [21] & 2011 & Jordan & 0.433 & no & yes & no & no & 0.5 & 54 \\
\hline [13] & 2012 & Marseille, France & 0.5 & no & no & no & no & 1 & not mentioned \\
\hline [22] & 2012 & Jordan & 0.432 & no & yes & no & no & $5.7(24 h)$ & no \\
\hline [23] & 2012 & Egypt & 5 & not mentioned & yes & no & no & $5(24 h)$ & no \\
\hline [24] & 2013 & $\begin{array}{l}\text { Dhahran, Saudi } \\
\text { Arabia }\end{array}$ & 2.4 & 2 & yes & no & no & $5(12 h)$ & not mentioned \\
\hline$[25]$ & 2013 & Amarika, Namibia & 19.8 & no & yes & no & no & 3.3 & 23 \\
\hline [26] & 2014 & Nairobi, Kenya & 5 & 1 & yes & 1.5 & no & 3.5 & no \\
\hline [26] & 2014 & Nyala, Sudan & 5 & 1 & yes & 1.5 & no & 3.5 & no \\
\hline [27] & 2015 & Egypt & 2.5 & no & no & no & no & $4-5$ & not mentioned \\
\hline$[28]$ & 2015 & India & $0.075-3$ & no & yes & no & no & $1.04(4 h)$ & no \\
\hline [29] & 2015 & $\begin{array}{l}\text { La Mancalona, } \\
\text { Mexican }\end{array}$ & 0.4 & no & yes & no & no & 1 & 33 \\
\hline [30] & 2015 & India & $\begin{array}{l}\text { not mentioned } \\
\text { (with \& without } \\
\text { freshwater } \\
\text { storage) }\end{array}$ & no & no & no & no & $2.4-6$ & no \\
\hline [31] & 2016 & Bangi, Malaysia & 2 & no & yes & no & no & $5.1(10 h)$ & not mentioned \\
\hline$[32]$ & 2016 & Pakistan & 0.75 & no & yes & no & no & $0.0295(5 h)$ & not mentioned \\
\hline [32] & 2016 & Pakistan & 0.12 & no & no & no & no & $0.0266(7 \mathrm{~h})$ & not mentioned \\
\hline [33] & 2016 & $\begin{array}{l}\text { St. Dorcas } \\
\text { borehole, } \\
\text { Tanzania }\end{array}$ & 0.3 & no & no & no & no & $1.3-1.6$ & $23.1-27.8$ \\
\hline [34] & 2017 & Saudi Arabia & 0.25 & no & no & no & no & 0.126 & not mentioned \\
\hline [35] & 2018 & $\begin{array}{l}\text { South Khorasan, } \\
\text { Iran }\end{array}$ & not mentioned & not mentioned & yes & no & yes & 10 & no \\
\hline [36] & 2019 & Tanzania & 2.25 & no & yes & no & no & 2.36 & $6-18$ \\
\hline [8] & 2020 & Pakistan & 2 & no & no & no & no & $4(8 h)$ & no \\
\hline
\end{tabular}

54 Combining RESs with energy storage device has the advantage of providing constant energy flow during 55 insufficient power generation time and offering the ability to buffer the energy production variations. Nonetheless, 56 besides to the environmental issues, the capital and maintenance cost of batteries (and/or burned fuel cost) is often 
a major concern [37], especially for remote and poverty areas. Therefore, minimizing or even suppressing the energy storage device such as electrochemical storage means is a challenging issue facing such standalone desalination systems, especially in the light of continuous freshwater supply.

In case of RES-RO desalination system without batteries, freshwater will be produced by a variable and discontinuously operated desalination system. That is, RO membrane will operate under variable feed pressure. It has been demonstrated that the operation of the RO membrane under variable power supply remains unaffected [38-39]. Moreover, several studies at the laboratory scale have demonstrated the possibility of operating RES-RO desalination units without battery storage device [40-42]. Another study concluded that it is possible to completely eliminate batteries in PV-RO systems; it needs to automatically adjust the operating point of the RO-pump with fluctuating solar energy [43]. An economic analysis was also conducted in [32] for PV-RO system with and without battery, where results demonstrated that battery-less PV-RO system is more economically suitable than that using battery storage. A comprehensive review of desalination technologies powered by solar energy including solar PV-RO desalination systems without batteries was conducted in [44]. It is concluded that coupling $\mathrm{RO}$ and PV systems is relatively straightforward, especially for small-scale units.

Another option to reduce the capital cost is to store water in a storage tank such as the example of using buffer tank for freshwater storage [30] [45]. Such an alternative enables to minimize the needed number of batteries and overcome the challenge of longer-term renewable energy variation. In ref. [30], authors showed that the system productivity increased up to $36 \%$ by storing produced freshwater. It was demonstrated that a buffer tank can be considered as a surrogate energy storage device. The concept is that the generated renewable energy during sunny and/or windy days is a stored energy in the form of water. This can be considered very cost-effective and environmentally friendly alternative compared with RES-RO units using battery banks or diesel generator backup. In this context, a focus on a standalone small-scale Brackish Water Reverse Osmosis (BWRO) desalination system in rural area is put forward in this paper. This system is powered by hybrid PV/Wind turbine source without electrochemical storage device, but exploiting hydraulic storage (brackish water and freshwater) in storage tanks. The idea is: $i$ ) to take advantage of storing the well brackish water and the produced freshwater in tanks when renewable energy is available, and ii) to exploit motor-pumps modularity (i.e. several pumping subsystems that can be switched on/off and tuned) versus the given generated power. For this sake, an experimental BWRO desalination unit at the laboratory scale (freshwater production of 300 liters/h) using an elevated brackish water storage tank was designed and mounted to investigate the feasibility and reliability of PV/Wind-BWRO desalination system in rural areas. A second storage tank is also used in this unit to store the produced freshwater, for later use when renewable energy is unavailable.

To overcome the variable and discontinuously operated PV/Wind-BWRO unit, a specific energy (power and water flows) management is then required in order to manage simultaneously power and water flows into the desalination system while fulfilling technological (power and pressure ranges) and functional (tank filling state) constraints of the system. The energy management strategy to be developed must take into consideration the strongly coupled system design: "water/power management and device sizing". In particular, the generated power from RESs is strongly coupled with the water process system efficiency. In addition to that, the coupling between sizing and management performance is of a paramount importance in this study. Therefore, it is mandatory to study the sizing of pumps and the different pump-combinations in the desalination system to get an optimal 
generated power. All of these aspects put forward the necessity of a "systemic design approach" integrating the strong coupling between architecture (modularity), sizing and flow (power, water) management. In this regard, authors in ref. [46] have investigated a global optimization approach taking account of the couplings between the system architecture, sizing and energy management. They proposed an optimization dispatching algorithm for sharing the variable input power between the three installed motor-pumps: the choice of the objective function for the optimization algorithm to evaluate the operating efficiency has been justified. The influence of the pump sizing on the system efficiency has been also analyzed.

This paper proposes a first design approach based on specific modeling and management strategy. It primarily aims to maximize as much as possible the water production of the system according to the renewable energy generation. First, a quasi-static modeling stemming from dynamic modeling of the experimental BWRO desalination test bench is developed for simulations. In order to validate the developed model, the latter is compared with the experimental model obtained from experimental characterizations of the BWRO test bench. Then, an energy management strategy is developed using Deterministic Rule-based power sharing algorithm. Such algorithm should conveniently dispatch the instantaneous generated power between the different water process subsystems into the studied system while taking into consideration: $i$ ) the aforementioned system constraints, and $i$ ) the objective of maximizing freshwater production. For the sake of optimality, the sizing influence of both pump combinations and brackish water storage tank capacity on the energy management performance is then analyzed. As regards the capacity sizing of the freshwater storage tank, it is not studied during simulations and analysis, since it is viewed as an infinite storage tank (in simulations) aiming to store a maximum amount of produced freshwater.

This paper is organized as follows: the architecture and specifications of the BWRO desalination system are described in Section 2. The adopted systemic design approach is defined in Section 3. The analytical modeling of the studied system is detailed in Section 4. The EMS is described in Section 5. Section 6 is dedicated to analyze the simulation results. In this Section the influence of pumps and tank capacity sizing on the energy management performance are investigated and analyzed. Finally, main conclusions and prospects are summarized in Section 7.

\begin{tabular}{|c|c|c|c|}
\hline \multicolumn{4}{|c|}{ Nomenclature } \\
\hline \multicolumn{4}{|c|}{ Acronyms } \\
\hline BWRO & Brackish Water Reverse Osmosis & $g$ & gravity acceleration, $\mathrm{N} / \mathrm{Kg}$ \\
\hline $\mathrm{CV}$ & Control Valve of the RO membrane & $H_{g e o}$ & geodetic head that the pump must overcome, $\mathrm{m}$ \\
\hline DC & Direct Current & $H_{\text {tank }}$ & height of the stored brackish water amount in tank $T_{1}, \mathrm{~m}$ \\
\hline EMS & Energy Management Strategy & $H_{a s p}$ & brackish water aspiration height of the HPP, $m$ \\
\hline HPP & High Pressure Pump & $H M T$ & total dynamic head of the pump, $\mathrm{m}$ \\
\hline $\mathrm{IM}$ & Induction Motor & $P_{\text {feed }}$ & feed pressure of the RO membrane, bar \\
\hline PV & Photovoltaic & $P_{a s p}$ & brackish water aspiration pressure of the HPP, bar \\
\hline RES & Renewable Energy Source & $P_{\text {tank }}$ & resulting pressure from stored amount of brackish water in the \\
\hline RO & Reverse Osmosis & & $\operatorname{tank} T_{1}$, bar \\
\hline WP & Well Pump & $P_{\text {hyd_load }}$ & required pressure of a hydraulic load, bar \\
\hline \multirow{2}{*}{\multicolumn{2}{|c|}{ Greek symbols }} & $P_{H P P}$ & proper pressure given by the HPP, bar \\
\hline & & $\mathcal{P}_{d c}$ & renewable generated power transferred via a DC bus, $\mathrm{W}$ \\
\hline$\alpha$ & power sharing factor, - & $\mathcal{P}_{H P P}$ & assigned electric power to the HPP, W \\
\hline$\rho$ & water density, $\mathrm{Kg} / \mathrm{m}^{3}$ & $\mathcal{P}_{W P}$ & assigned electric power to the WP, W \\
\hline $\begin{array}{l}\varphi_{r} \\
\varphi_{r d}\end{array}$ & $\begin{array}{l}\text { rotor flux of the induction motor, } \mathrm{Wb} \\
\mathrm{d} \text {-axis rotor flux in the }(\mathrm{d}, \mathrm{q}) \text { reference frame, } \mathrm{Wb}\end{array}$ & $\mathcal{P}_{\min }$ & minimum electric power, $\mathrm{W}$ \\
\hline
\end{tabular}




\begin{tabular}{|c|c|c|c|}
\hline$\varphi_{r q}$ & $\mathrm{q}$-axis rotor flux in the $(\mathrm{d}, \mathrm{q})$ reference frame, $\mathrm{Wb}$ & $\mathcal{P}_{\max }$ & maximum electric power, $\mathrm{W}$ \\
\hline$\Omega$ & angular speed of the induction motor, $\mathrm{rad} / \mathrm{s}$ & $Q_{p}$ & pump flowrate, liters/min \\
\hline \multirow{2}{*}{\multicolumn{2}{|c|}{ Variables/parameters }} & $Q_{\text {fresh }}$ & freshwater flowrate, liters/min \\
\hline & & $Q_{\text {feed }}$ & feed water flow of the RO membrane, liters/min \\
\hline$F S$ & filling state of the storage tank $T_{1}, \%$ & $Q_{\text {reject }}$ & rejected water flow rate of the $\mathrm{RO}$ membrane, liters/min \\
\hline$F S_{0}$ & initial filling state of the tank $T_{1}, \%$ & $Q_{W P}$ & well pump flowrate, liters/min \\
\hline$F S_{\max }$ & maximum limit of the tank filling state, $\%$ & $Q_{H P P}$ & high pressure pump flowrate, liters/min \\
\hline$F S_{\min }$ & minimum limit of the tank filling state, $\%$ & $q_{\text {fresh }}$ & produced freshwater quantity, $\mathrm{m}^{3}$ \\
\hline$I_{p}$ & consumed current by the pump, A & $R_{s}$ & stator resistance of the induction motor, Ohms \\
\hline$I_{s d}$ & $d$-axis stator current in the $(d, q)$ reference frame, $A$ & $R_{r}$ & rotor resistance of the induction motor, Ohms \\
\hline$I_{s q}$ & $\mathrm{q}$-axis stator current in the $(\mathrm{d}, \mathrm{q})$ reference frame, $\mathrm{A}$ & $S_{1}$ & surface area of the storage tank $T_{1}, \mathrm{~m}^{2}$ \\
\hline$I_{c}$ & current of the DC-link capacitor, A & $T_{1}$ & storage tank of brackish water, - \\
\hline$I_{d c}$ & DC-link current, A & $T_{p}$ & pump torque, N.m \\
\hline$L_{m}$ & mutual inductance in the induction motor, $\mathrm{H}$ & $T_{m}$ & motor torque, N.m \\
\hline$L_{r}$ & rotor inductance in the induction motor, $\mathrm{H}$ & $V_{d c}$ & DC-link voltage, $\mathrm{V}$ \\
\hline$L$ & water level in the storage tank $T_{1}, \mathrm{~m}$ & $V_{s d}$ & $d$-axis of the stator voltage in the $(d, q)$ reference frame, $V$ \\
\hline$L_{\min } \operatorname{Inf}$ & inferior minimum limit level in the storage tank, $\mathrm{m}$ & $V_{s q}$ & $\mathrm{q}$-axis of the stator voltage in the $(\mathrm{d}, \mathrm{q})$ reference frame, $\mathrm{V}$ \\
\hline$L_{\min }$ Sup & superior minimum limit level in the storage tank, $\mathrm{m}$ & $\Delta P_{\text {pipe }}$ & pressure drop in pipelines, bar \\
\hline \multirow{3}{*}{$\begin{array}{l}L_{\max }^{\operatorname{Inf}} \\
L_{\max } \text { Sup }\end{array}$} & inferior maximum limit level in the storage tank, $\mathrm{m}$ & $\Delta \mathcal{P}_{I M}$ & electrical power losses through the induction motor associated \\
\hline & superior maximum limit level in the storage tank, $\mathrm{m}$ & & with its inverter, W \\
\hline & & $\Delta \mathcal{P}_{p}$ & hydraulic power losses through the centrifugal pump \\
\hline
\end{tabular}

\section{Description of the BWRO desalination system}

\subsection{System architecture overview}

The studied system, depicted in Fig.1, consists of small-scale standalone brackish water pumping and desalination unit. It is mainly composed of two hydro-mechanical subsystems:

1) "Water Pumping Process" that uses well Pump(s) (WP) to pump brackish water from the well to an elevated storage tank $T_{1}$. This process is dedicated for gravitational brackish water storage.

2) "Reverse Osmosis (RO) Desalination Process" enabling to produce freshwater using a RO membrane(s) fed by a High Pressure Pump (HPP). The HPP exploits the stored amount of brackish water in the tank $T_{1}$ to feed the RO membranes under high pressure. The produced freshwater is stored in the tank $T_{2}$.

This unit would be powered via a Direct Current (DC) bus with a variable generated power $\mathcal{P}_{\mathrm{dc}}$ offered along wind speed and solar irradiation conditions (PV/Wind turbine) without battery storage.

The hydraulic architecture of the desalination system depicted in Fig. 2 is defined so that the desalination system includes two independent hydraulic subsystems decoupled through the elevated water storage tank $T_{1}$. The latter presents the first key element of the chosen architecture. In other words, pumped brackish water from the well can be stored into the elevated tank $T_{1}$, when renewable energy is available, for later or simultaneous use by the RO desalination process to produce freshwater. The latter in turn is stored in high capacity tank $T_{2}$, for later use when the renewable energy is unavailable. This constitutes the second key element of the system architecture. Therefore, the electrochemical storage device can be replaced by hydraulic storage (brackish water and freshwater) in water tanks. 


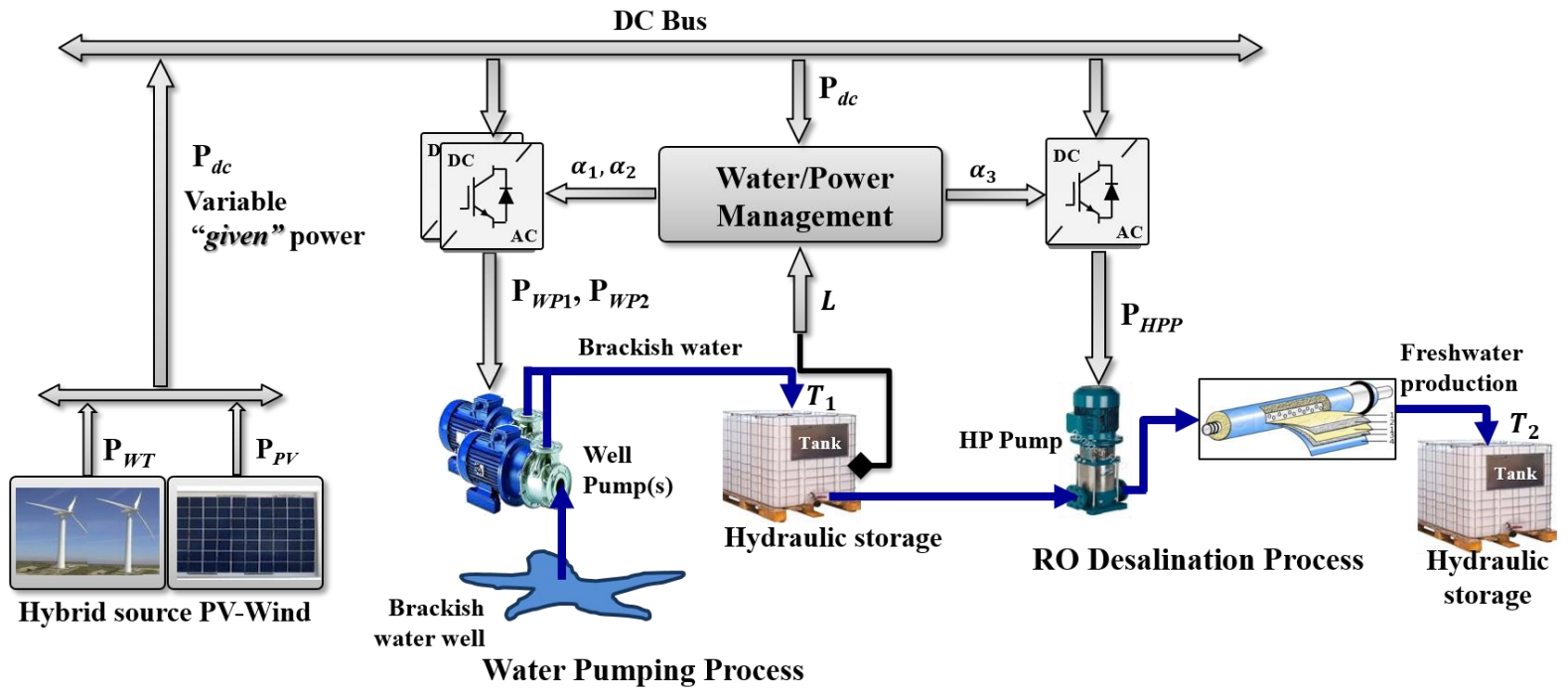

Fig.1. Synoptic of the autonomous BWRO desalination system

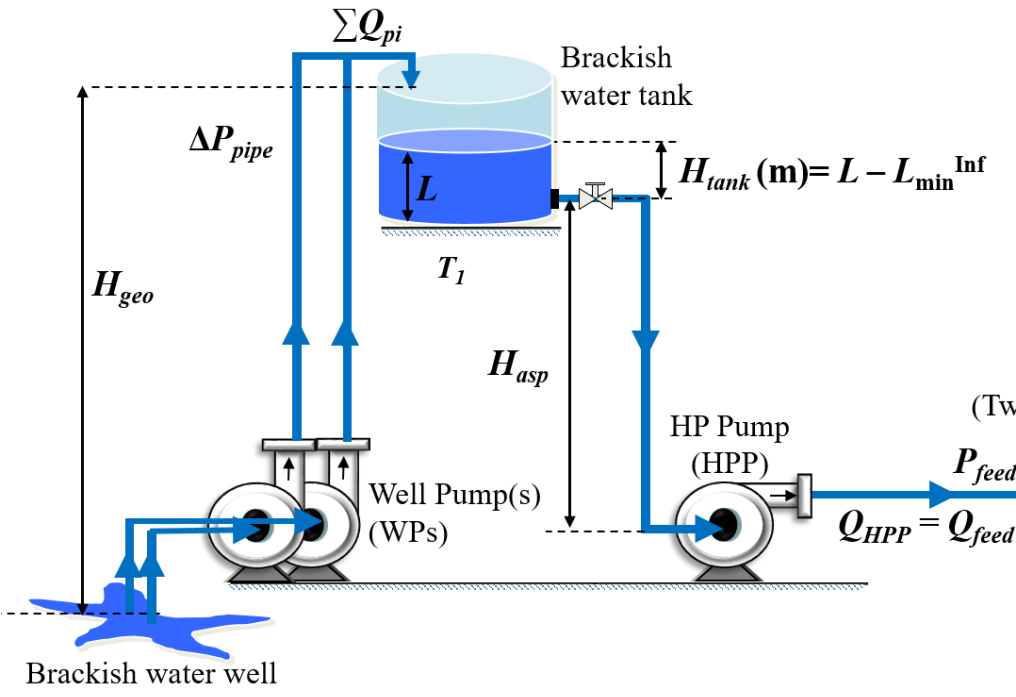

Fig.2. Hydraulic configuration of the BWRO desalination system
Hydraulic load (Two RO membranes)

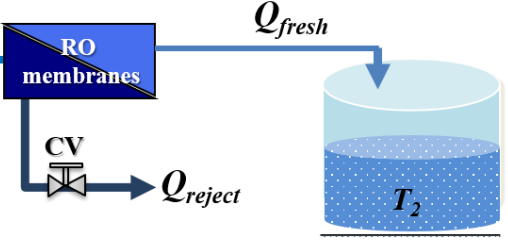

Freshwater tank

\subsection{Experimental test bench}

An experimental test bench, shown in Fig.3, was designed and mounted in our research laboratory (L.S.E in ENIT-UTM, Tunis, Tunisia). The synoptic scheme of the experimental test bench is depicted in Fig.4. The specifications of the presented test bench are reported in Table 2. This experimental unit is used for the experimental characterizations of the hydro-mechanical processes in order to validate the system model. Indeed, the two hydro-mechanical processes have been experimentally characterized and dynamically modeled in previous studies [47-50].

Based on the dynamic modeling of hydro-mechanical processes of the presented RO unit, a quasi-static modeling is developed for energy management which is described in Section 4. 

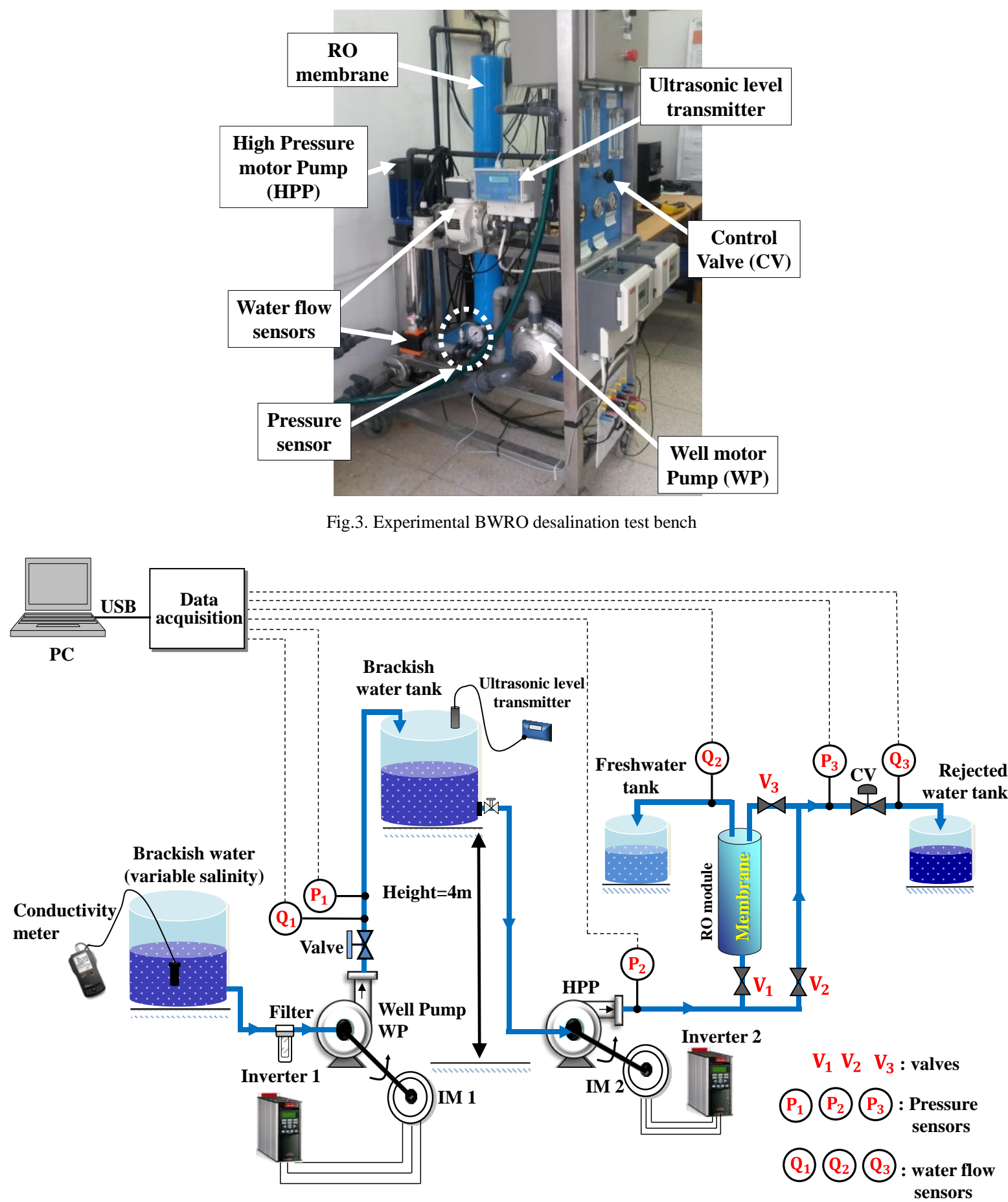

Fig.4. Sysnoptic scheme of the experimental BWRO desalination test bench

Table 2 Specifications of the experimental desalination test bench

\begin{tabular}{|c|c|c|}
\hline Components & Characteristics & Component constraints \\
\hline High Pressure Pump (HPP) & $\begin{array}{l}\text { Model: EBARA EVM2 22F/2.2 } \\
\text { Type: centrifugal 3-ph motor pump } \\
\text { Power output: } 2.2 \mathrm{~kW} \\
\text { Rated Pressure: } 8.17-18.6 \mathrm{bar} \\
\text { Rated flow rate: } 20-601 / \mathrm{min}\end{array}$ & $\begin{array}{l}\text { Minimum absorbed electric power: } 620 \mathrm{~W} \\
\text { Maximum absorbed electric power: } 1800 \mathrm{~W}\end{array}$ \\
\hline Well Pump $1\left(\mathrm{WP}_{1}\right)$ & $\begin{array}{l}\text { Model: PEDROLLO CP158 } \\
\text { Type: centrifugal 3-ph motor pump } \\
\text { Power output: } 0.75 \mathrm{~kW} \\
\text { Rated Pressure: } 2.5-3.4 \mathrm{bar} \\
\text { Rated flow rate: } 10-901 / \mathrm{min}\end{array}$ & $\begin{array}{l}\text { Minimum absorbed electric power: } 120 \mathrm{~W} \\
\text { Maximum absorbed electric power: } 1020 \mathrm{~W}\end{array}$ \\
\hline Well Pump $2\left(\mathrm{WP}_{2}\right)$ & $\begin{array}{l}\text { Model: LOWARA CEA70/3 } \\
\text { Type: centrifugal 3-ph motor pump } \\
\text { Power output: } 0.37 \mathrm{~kW}\end{array}$ & $\begin{array}{l}\text { Minimum absorbed electric power: } 120 \mathrm{~W} \\
\text { Maximum absorbed electric power: } 370 \mathrm{~W}\end{array}$ \\
\hline
\end{tabular}


Rated Pressure:1.3-2 bar

Rated flow rate: $30-801 / \mathrm{min}$

\begin{tabular}{lll} 
RO membrane & Model: TORAY TM710 & Minimum feed pressure: $8.4 \mathrm{bar}$ \\
& Feed water salinity: $4 \mathrm{~g} / \mathrm{l}$ & \\
& Maximum freshwater production: $300 \mathrm{l} / \mathrm{h}$ & Maximum feed pressure: $16.2 \mathrm{bar}$ \\
& & \\
Capacity: $2.18 \mathrm{~m}^{3}$ & Inferior minimum limit level $L_{\min }$ Inf. $0.2 \mathrm{~m}$ \\
& Height: $2.1 \mathrm{~m}$ & Superior minimum limit level $L_{\min }: 0.25 \mathrm{~m}$ \\
& Elevation height: $4 \mathrm{~m}$ & Inferior maximum limit level $L_{\max }: 1.9 \mathrm{~m}$ \\
& Superior maximum limit level $L_{\max }: 2 \mathrm{~m}$ \\
\hline \hline
\end{tabular}

\subsection{Characteristic specificity of the chosen architecture}

Due to the hydraulic processes decoupling, the system has more degrees of freedom than conventional used architecture where motor-pumps are usually coupled in series (without brackish water storage tank). In fact, the system can independently operate as: $i$ ) "pumping system" by operating solely the water pumping process in case of low level of generated power, or ii) "RO desalination system" by operating solely the RO desalination process in case of high level of generated power, or also iii) "pumping and RO desalination system" in case of very high level of generated power. In the latter operating mode, the two hydraulic processes operate simultaneously to pump brackish water from the well to fill the storage tank and, in the same time, produce freshwater using the pumped brackish water from $T_{1}$. Indeed, this configuration offers a great flexibility for the experimental characterization of each hydro-mechanical process.

Within this hydraulic configuration, the "gravitational water storage" involves an advantage of great importance in terms of energy efficiency improvement; this fact enables to take benefit of an additional free hydraulic energy boosting the RO desalination energy efficiency. As a result, freshwater productivity can be improved. This point has been highlighted in previous work [51]. Moreover, besides the advantage of being environmentally friendly, another advantage of using hydraulic storage over electrochemical storage device is the simplicity of such a configuration (no need to control laws), as well as it offers lower cost alternative (no need to additional power converters for control and no maintenance requirements).

On the other hand, the studied system is classified among complex energy systems. Its complexity is characterized by the combination of components of different natures and functionalities, all interacted within the system under study. Such heterogeneity leads to several physical phenomena coexistence, and several system constraints of different domains. These constraints can be listed as: $i$ ) functioning under variable energy supply (i.e. variable feeding power and pressures), ii) technological constraints of pumping devices (power ranges) and RO membrane (flow-pressure range), and iii) functioning constraints (i.e. filling state of the storage tank). This makes the modeling and the flow (power, water) management of the system a difficult task.

Given the diversification of the system constraints, it becomes necessary to move towards a new approach permitting to connect all system components by integrating "intra"- and "inter-disciplinary" coupling. This methodology is based on the "systemic design approach" [52] described in the following section.

\section{Definition of the systemic design approach}

The adopted systemic design approach is described in Fig. 5. It relies on the choice of: $i$ ) architecture and components, ii) sizing, and iii) development of control/management process. The design has to meet requirements defined by the bill of specifications. This consititutes a fundamental and preliminary step for the designer. Therefore, satisfying the bill of specifications needs a "synthesis" (i.e. structure determination) and 
"sizing" (i.e. parameters determination) that meet: $i$ ) these requirements while anticipating by "simulation" and "analysis" (Fig.5) of the system being designed, ii) system performance, and iii) system constraints.

The systemic design approach is an iterative process based on three main phases:

- Phase 1: the choice of the system architecture (as defined in the previous section). This allows performing the modeling and simulation of these components.

- Phase 2: the optimal pre-sizing of the system components. Such a phase allows characterizing of these elements and specifying the instantaneous energy transfers during an idealized operating cycle. This leads to understand the energy behavior of the system.

- Phase 3: the optimization of the energy flows into the system with the objective of determining the optimal energy management of the system.

Therefore, following the energy optimization and the simulation of the system behavior it may happen that the components previously chosen are oversized or undersized. For that reason, the "system sizing - energy optimization" cycle is repeated several times off-line in order to refine the system specifications. The objective here is to design a system that should be well adapted to the energy management strategy which, in turn, will be implemented on-line. For this sake, several iterations are performed in this work as part of the systemic design by testing several combinations of different sized pumps and even different storage tank capacities. At each iteration, the architecture is defined, then, the system components are characterized and modeled based on the experimental set-up. This provides deep understanding of the system energy behavior. At the end of the cycle, the proposed energy management strategy is applied to the chosen architecture, and obtained results are analyzed.

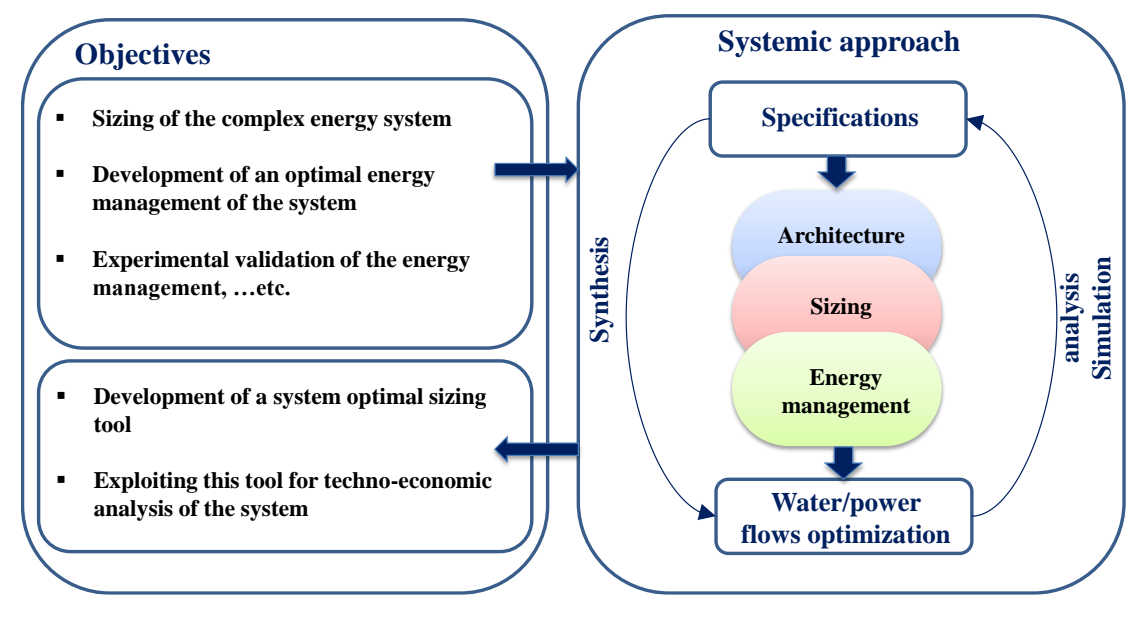

Fig.5. Optimization process of a complex energy system by the systemic approach

\section{System modeling}

This study focuses on the steady-state functioning of the system in order to simplify the energy management task. The quasi-static model constitutes a "power flow model" derived from dynamic energy behavior throughout the desalination chain. Therefore, in order to develop the quasi-static model of the hydro-mechanical system, several physical fields have to be considered. As depicted in Fig.6, it consists of the following subsystems from right to left: hydraulic load, centrifugal pump, and three phase induction motor fed and controlled by a voltage source inverter. The subsystems are linked each other by power flow variables: electrical voltage and current $\left(V_{\mathrm{dc}}, I_{p}\right)$, motor-pump torque and speed $\left(T_{p}, \Omega\right)$, and pump flow rate and pressure $\left(Q_{p}, P_{p}=\rho g H M T\right)$. The $H M T$ describes the 
total dynamic head (in meter) which depends on hydraulic load and pressure losses in pipelines $\Delta P_{\text {pipe }}, \rho$ is the water density and $g$ is the gravity acceleration.

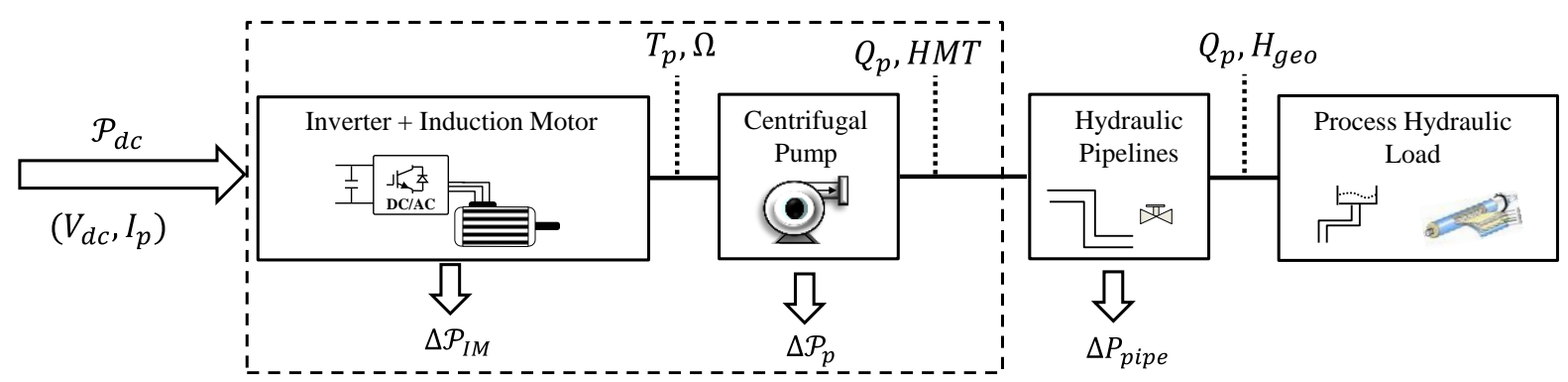

Fig. 6. Synoptic of the quasi-static modeling of a single-pump hydro-mechanical process: a power flow model

This section is divided into five parts: the first one is devoted for the modeling of the hydraulic subsystems (i.e. hydraulic loads). The second part presents the storage tank analytical model. The third part describes the hydromechanical subsystems modeling. Then, the analytical quasi-static model of a hydro mechanical process is presented in the fourth part. The last one is dedicated to the practical validation of the quasi-static model for each hydro-mechanical process.

\subsection{Hydraulic subsystems modeling}

As depicted in Fig.1 and Fig.2, we have two different hydro-mechanical subsystems decoupled through a storage $\operatorname{tank} T_{1}$. The modeling task here depends on the hydraulic load type of each subsystem:

1) In case of typical load as for the "first water subsystem", where the water is moved from one level (the well) to another (i.e. an elevated tank) as shown in Fig.2, a pressure drop in pipelines $\Delta P_{\text {pipe }}$ occurs. The latter is caused by the height difference $H_{g e o}$ (geodetic head that the pump must overcome), and the hydraulic losses depending on the pump water flow $Q_{p}=Q_{W P}$ [53-54]. Thus, the hydraulic load model of the first process (e.g. case of one well pump) is expressed by:

$\Delta P_{\text {pipe }}=\rho g H_{g e o}+k Q_{W P}^{2}$

where, $k$ is a constant.

2) The "second subsystem" is related to the water RO desalination process; it involves a complex and nonlinear hydraulic load (RO membrane + Control Valve (CV)) coupled to the HPP. The latter offers high water pressure to feed the RO membrane to produce freshwater. Based on the dynamic model of the RO membrane previously developed and detailed [48] and [55], the static model of the RO membrane expressed by (3), (4) and (5) is deduced by neglecting the dynamic elements effect, with some approximations:

$P_{\text {feed }}=\left(R_{\text {mod ule }}+R_{\text {valve }}\right) Q_{\text {reject }}^{2}$

$Q_{\text {fresh }}=\frac{P_{\text {feed }}}{R_{\text {membrane }}}$

$Q_{\text {feed }}=Q_{\text {fresh }}+Q_{\text {reject }}$

243 Where, $Q_{\text {feed }}$ and $P_{\text {feed }}$ denote respectively the feed flow rate and pressure of the RO membrane, $Q_{\text {fresh }}$ the produced

244 freshwater flow rate, $Q_{\text {reject }}$ the rejected water flow rate (very salted water), and $\left(R_{\text {module }}, R_{\text {valve }}, R_{\text {membrane }}\right)$ are the RO membrane parameters whose experimental values are reported in Table 3. Indeed, hydraulic losses into the RO process via the control valve $\mathrm{CV}$ (Fig.2), the RO module and the RO membrane are modeled as resistances 
such as $R_{\text {module }}, R_{\text {valve }}, R_{\text {membrane. }}$ It should be noted that a RO module can include one or several RO membranes coupled in series. In the studied case, each module contains one RO membrane.

Based on (2), (3) and (4), the static model of the hydraulic load (i.e. RO module) of the second process is deduced and expressed by (5) with respect to $Q_{\text {feed }}$.

$P_{\text {feed }}=\left(\sqrt{\frac{R_{\text {membrane }}^{2}}{4\left(R_{\text {mod ule }}+R_{\text {valve }}\right)}+R_{\text {membrane }} Q_{\text {feed }}}-\frac{R_{\text {membrane }}}{2 \sqrt{R_{\text {mod ule }}+R_{\text {valve }}}}\right)^{2}$

251 According to the hydraulic structure of the desalination process depicted in Fig.2, the feed pressure $P_{\text {feed }}$ of the RO 252 module results from the sum of different pressures as follows:

$$
\begin{aligned}
P_{\text {feed }} & =P_{H P P}+P_{\text {tank }}+P_{a s p} \\
& =P_{H P P}+\rho g\left(L-L_{\min }^{\mathrm{Inf}}\right)+\rho g H_{a s p}
\end{aligned}
$$

253 Where, $P_{H P P}$ denotes the proper pressure given by the HPP which is expressed in the next subsection by (8), $P_{\text {tank }}$

254 is the resulting pressure from the stored amount of brackish water in the tank $T_{1}, H_{a s p}$ and $P_{a s p}$ denote respectively the brackish water aspiration height and pressure of the HPP.

\subsection{Storage tank modeling}

A storage tank is characterized by the stored water level $L$. The first tank $T_{1}$ is modeled by (7) describing a timevarying model.

$$
L(t+\Delta t)=L(t)+\frac{1}{S_{1}} \int_{t}^{t+\Delta t}\left(Q_{W P}(t)-Q_{H P P}(t)\right) d t
$$

where, $S_{1}$ being the surface area of $T_{1}$, and $\left(Q_{W P}\right.$ and $\left.Q_{H P P}\right)$ denote respectively the well pump and the HP pump flow rates (i.e. input and output flow rates of the tank).

\subsection{Hydro-Mechanical subsystem modeling}

The static model of a centrifugal pump is obtained by neglecting the dynamic elements effect from its dynamic model performed in previous work [48]. Thus, the static part of a centrifugal pump is modeled as follows:

$$
\begin{gathered}
P_{p}\left(\Omega, Q_{p}\right)=\left(a \Omega+b Q_{p}\right) \Omega+c Q_{p}^{2} \\
T_{p}\left(\Omega, Q_{p}\right)=\left(a \Omega+b Q_{p}\right) Q_{p}+f_{p} \Omega
\end{gathered}
$$

Where, $P_{p}$ being the water pump pressure, $Q_{p}$ the pump flow rate, $T_{p}$ the pump torque, $\Omega$ the motor-pump angular speed, and $f_{p}$ is the coefficient of the hydraulic friction in the pump. The pump parameters $\left(a, b, c, f_{p}\right)$ have been experimentally identified and are reported in Table 3.

Table 3 Hydraulic parameters of different components of the experimental desalination test bench

\begin{tabular}{llll}
\hline \hline Component & Parameter & Value & Unit \\
\hline HPP & $a$ & 0.0002317 & $\mathrm{Ns}^{2} / \mathrm{m}^{2}$ \\
& $b$ & -0.0005198 & $\mathrm{Ns}^{2} / \mathrm{m}^{2}$ \\
& $c$ & -0.002427 & $\mathrm{Ns}^{2} / \mathrm{m}^{2}$ \\
& $f_{p}$ & 0.0038 & $\mathrm{Nms}$ \\
$\mathrm{W}_{\mathrm{P} 1}$ & $a$ & $4 \mathrm{e}-5$ & $\mathrm{Ns} 2 / \mathrm{m}^{2}$ \\
& $b$ & $-1.767 \mathrm{e}-5$ & $\mathrm{Ns}^{2} / \mathrm{m}^{2}$ \\
& $c$ & 0.0002 & $\mathrm{Ns}^{2} / \mathrm{m}^{2}$ \\
& $f_{p}$ & 0.0019 & $\mathrm{Nms}^{2}$ \\
$\mathrm{WP}_{2}$ & $a$ & $2.446 \mathrm{e}-5$ & $\mathrm{Ns}^{2} / \mathrm{m}^{2}$ \\
& $b$ & $-6.507 \mathrm{e}-5$ & $\mathrm{Ns}^{2} / \mathrm{m}^{2}$
\end{tabular}




\begin{tabular}{llll} 
& $c$ & $21.205 \mathrm{e}-5$ & $\mathrm{Ns}^{2} / \mathrm{m}^{2}$ \\
& $f_{p}$ & 0.002 & $\mathrm{Nms}$ \\
RO Membrane & $R_{\text {module }}$ & $1.038 \mathrm{e} 12$ & $\mathrm{Ns}^{2} / \mathrm{m}^{8}$ \\
& $R_{\text {valve }}$ & $7.785 \mathrm{e} 12$ & $\mathrm{Ns}^{2} / \mathrm{m}^{8}$ \\
& $R_{\text {membrane }}$ & $1.695 \mathrm{e} 10$ & $\mathrm{Ns} / \mathrm{m}^{5}$ \\
\hline \hline
\end{tabular}

With regard to the three-phase Induction Motor (IM) driving the centrifugal pump, the Power Field Oriented Control (PFOC) method has been applied through the associated inverter as depicted in Fig.7. In such a case, the inverter is used to regulate the magnetic flux and control the torque being cascaded with the DC-link voltage control loop [56-57]. In the Park's d-q reference frame linked to rotating field, the rotor flux is controlled through the d-axis $\left(\varphi_{r d}=\varphi_{r}, \varphi_{r q}=0\right)$.

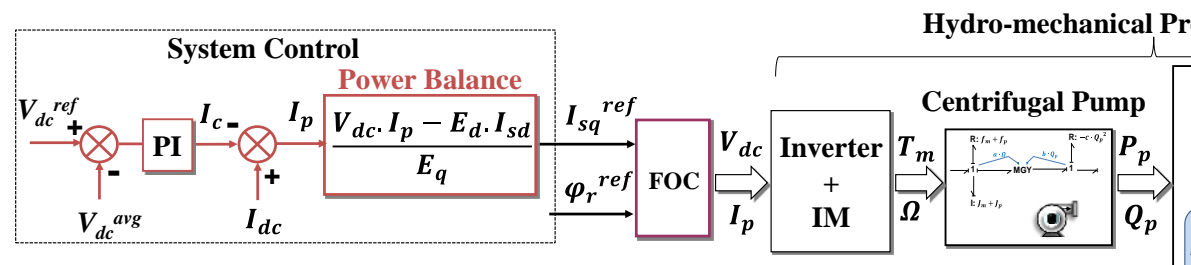

Fig.7. Block diagram of the control strategy of a single-pump hydro-mechanical process

By neglecting power losses via the inverter (denoted $\Delta \mathcal{P}_{I M}$ in Fig. 6), the power balance is given by:

$V_{\mathrm{dc}} I_{p}=V_{s q} I_{s q}+V_{s d} I_{s d}$

As a result, based on the above equation and the original equations of the stator and rotor voltages in the $d-q$ reference frame, while neglecting the dynamic elements (i.e. fast transients), the electrical power $\mathcal{P}_{I M}$ feeding the motor-pump can be expressed versus the angular speed and the electromagnetic torque $\left(\Omega, T_{m}\right)$. The latter variables are in turn expressed versus pump flow rate $Q_{p}$ and are given by (11) and (12).

$T_{m}\left(\Omega, Q_{p}\right)=T_{p}\left(\Omega, Q_{p}\right)+f_{m} \Omega$

$\Omega\left(Q_{p}\right)=\frac{-b Q_{p}+\sqrt{\left(b Q_{p}\right)^{2}-4 a\left(c Q_{p}^{2}-P_{\text {hyd-load }}\left(Q_{p}\right)\right)}}{2 a}$

Where, $P_{\text {hyd-load }}$ denotes the hydraulic load pressure describing the analytical model of the hydraulic load of each hydro-mechanical process. It should be pointed out that the full expression of the motor-pump angular speed $\Omega\left(Q_{p}\right)$ can be derived from (1) and (8) in case of "pumping process", and from (5), (6) and (8) in case of "desalination process", by choosing the positive root of the $2^{\text {nd }}$ order equation.

As a result, $\mathcal{P}_{I M}$ can be expressed with respect to the pump flow rate $Q_{p}$ by (13).

$\mathcal{P}_{I M}\left(Q_{p}\right)=R_{s r} \frac{\varphi_{r}}{L_{m}}-R_{r}\left(\frac{\varphi_{r}}{L_{r}}\right)^{2}+\left(\frac{R_{s r} L_{r}}{L_{m} \varphi_{r}} T_{m}\left(Q_{p}\right)\right)^{2}+\Omega\left(Q_{p}\right) T_{m}\left(Q_{p}\right)$

where,

$$
R_{s r}=R_{s}+R_{r}\left(\frac{L_{m}}{L_{r}}\right)^{2}
$$

The obtained equation (13) presents a nonlinear and multivariable expression of the feeding electrical power of the motor-pump with its corresponding hydraulic load. In order to determine the pump flow rate with respect to its 
feeding electrical power, (13) can be reversed by using the "fsolve" function under Matlab ${ }^{\odot}$ software. The inverse expression (i.e. $Q_{p}=f\left(\mathcal{P}_{I M}\right)$ ) describes the quasi-static model of a whole hydro-mechanical process in the desalination system.

\subsection{Practical validation of the quasi-static model}

293 In order to validate the developed models of the two hydro-mechanical processes, model-based simulation results

294 are compared to the models extracted from experimental characterizations (in steady-state) of each hydromechanical process of the desalination experimental set-up (for more details on the experimental characterizations see sub-section 3.2) in ref. [51]). This comparison is illustrated by Fig.8 that presents the water flow rate variation

297 curves $Q_{p}=f\left(\mathcal{P}_{I M}\right)$ for the three used motor-pumps (WP1, WP2 and HPP) with respect to the drawn electrical power by each motor-pump. According to this, an energetic coherence between the dynamic and quasi-static models of each hydro-mechanical process has been proved. These results put forward the great worth of the quasistatic modeling to be used in order to set and optimize the energy management strategy which is defined and discussed in the next section. 


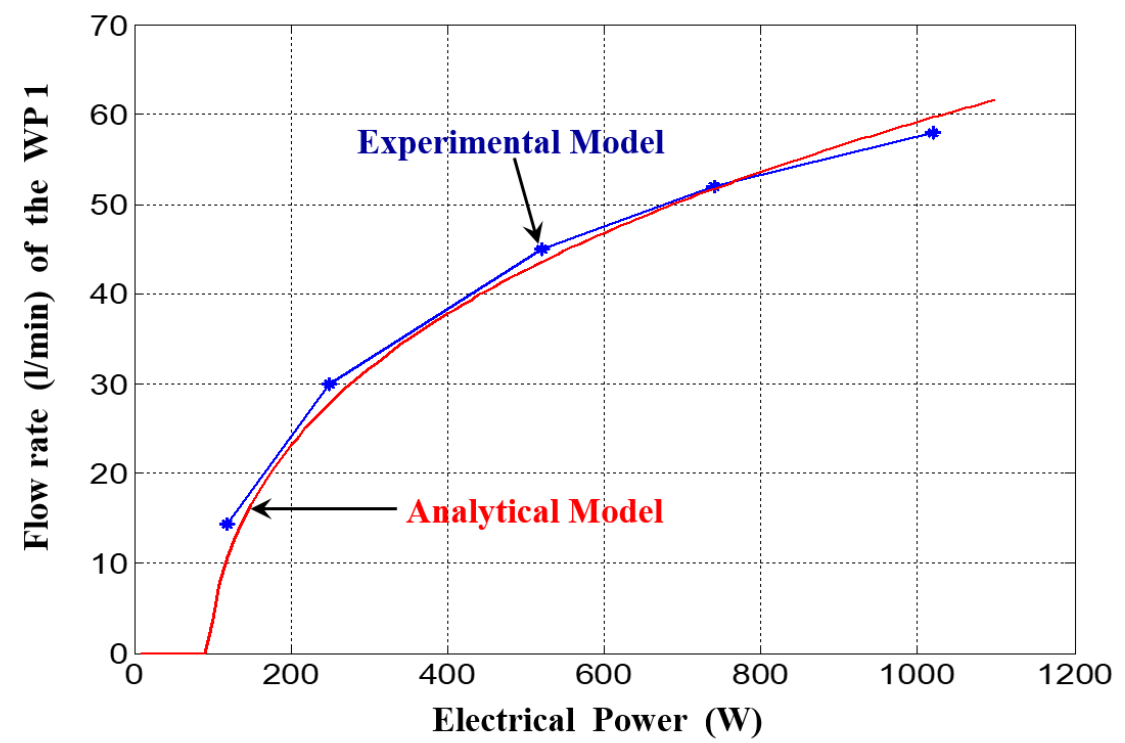

(a)

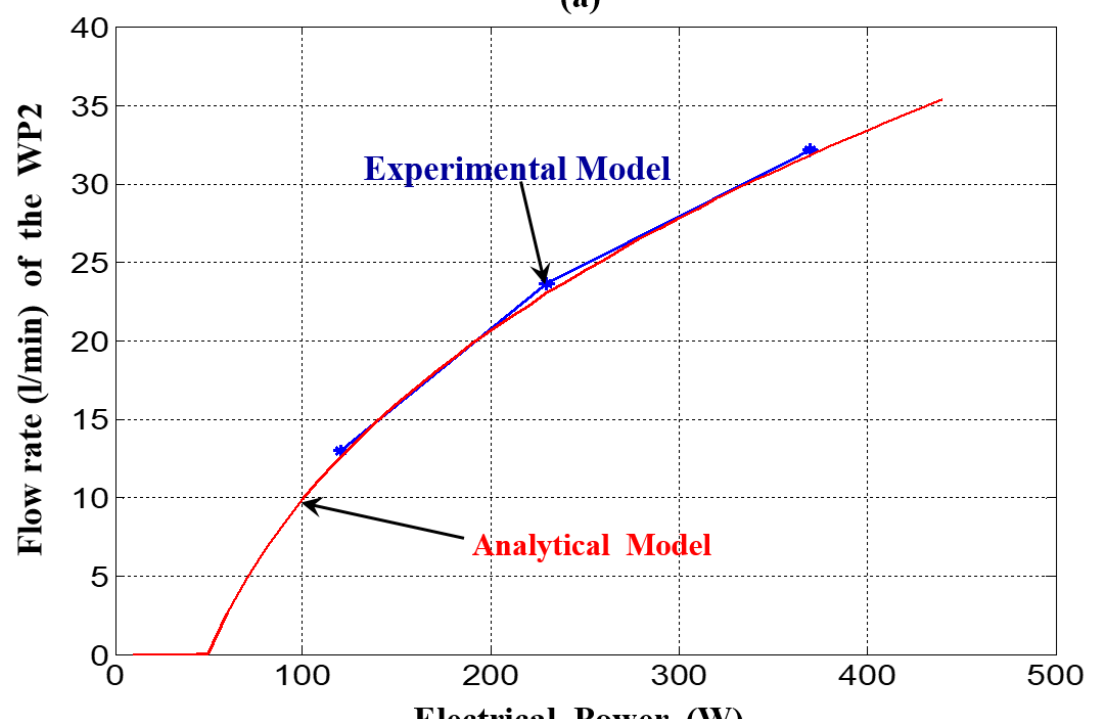

Electrical Power (W)

(b)

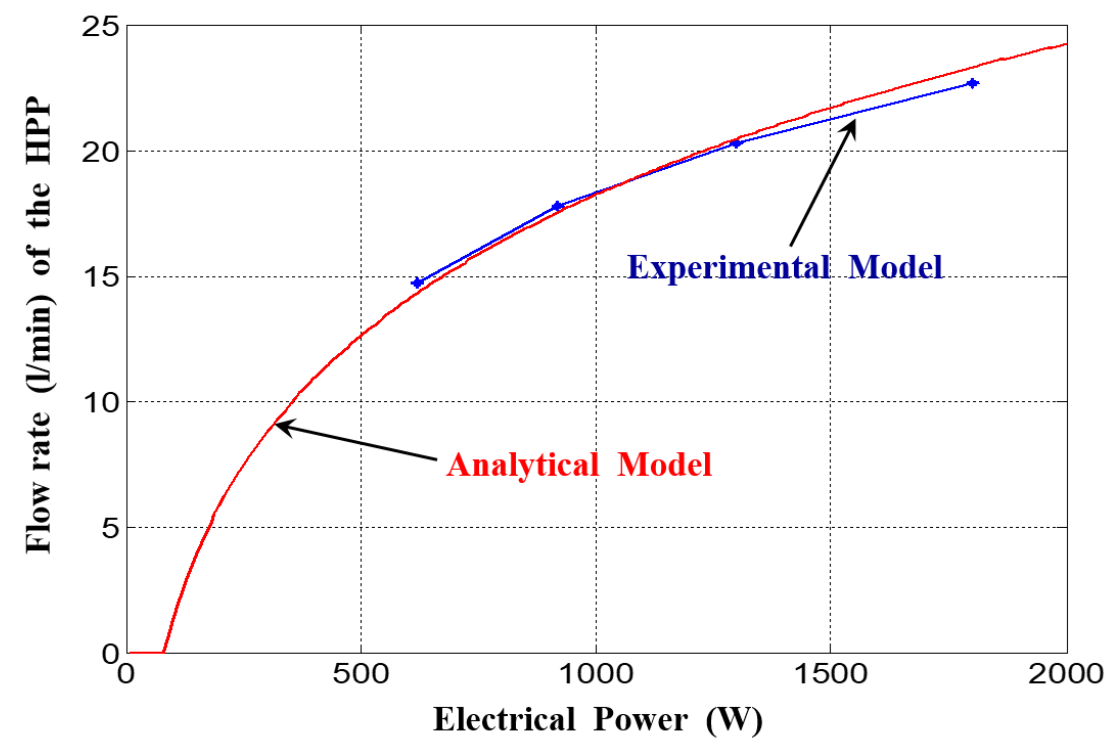

(c)

Fig.8. Comparison of the developed and experimental models for the different hydro-mechanical subsystems of (a) well pump WP1 (b) well 
This section is divided into two parts. The first one is devoted for setting the energy management problem. The second part is dedicated to describe the energy management strategy (EMS) that is based on deterministic rules.

\subsection{Setting the water/power management problem}

As electrochemical storage is substituted by hydraulic storage in water tanks, the desalination system includes two decoupled and independent hydro-mechanical subsystems. The energy requirements of these subsystems are not the same depending on their operating points. The latter depend on both the hydraulic characteristic curve of the pump (imposed following the rotational angular speed of the motor-pump) and the hydraulic load characteristic curve of each pump. This needs to develop a specific EMS permitting to manage simultaneously the power and water flows into the system while fulfilling the technological (power and pressure ranges) and functional (tank filling state) constraints. The principle of the proposed EMS is defined such as the input variable generated power from RESs can be dispatched between the different pumping devices according to a power sharing factor $\left(\alpha_{i}\right)$ defined as:

$\mathcal{P}_{p_{i}}=\alpha_{i} \mathcal{P}_{d c}$

With:

$\sum_{i=1}^{n} \alpha_{i}=1$

$\mathcal{P}_{p_{i}}{ }^{\text {min }} \leq \mathcal{P}_{p_{i}} \leq \mathcal{P}_{p_{i}}{ }^{\text {max }}$

$L_{\min }^{\mathrm{Inf}} \leq L \leq L_{\max }^{\mathrm{Sup}}$

Where $\mathcal{P}_{p i}$ and $\alpha_{i}$ denote respectively the electrical power that should be addressed to the $i^{\text {th }}$ motor-pump of the system, and its corresponding power sharing factor, $\mathcal{P}_{d c}$ denotes the input DC-link power to be dispatched, and $n$ is the total number of pumping devices.

The objective of the EMS described by equations (15), (16), (17) and (18) is to maximize the freshwater production of the system according to the available renewable energy generation while respecting the system constraints. Maximizing freshwater production following the available renewable energy is beneficial in terms of freshwater storage that presents a new form of energy storage. The idea is to maximize and store freshwater, for later use when renewable energy is unavailable.

The power value $\mathcal{P}_{p i}$ for the $i^{t h}$ switched-On pump is considered as reference value that should be given by the EMS based on (15). The choice of the $\mathcal{P}_{p i}$ value is constrained by both the power range of the $i^{\text {th }}$ motor-pump and the tank filling state confines as defined in (17) and (18), respectively. This principle is applied for all pumping devices. Thus, according to both input generated power and the $T_{1}$ filling state, the $\alpha_{i}$ value is computed and subsequently the $\mathcal{P}_{p i}$ value of each pump is determined. Then, according to the power value $\mathcal{P}_{p i}$ and to the operation time of each pump the brackish water level in the tank $T_{1}$ (defined by (7)) will be varied (i.e. increased or decreased). For example, in case of low value of $\alpha_{1}=\left(\mathcal{P}_{W P 1} / \mathcal{P}_{\mathrm{dc}}\right)$, the well pump (WP $)$ operates in the region of low efficiency due to the very low input power. For this reason, no remarkable increase in the water level can be noticed, but on the other side the high pressure pump (HPP) operates with high input power and good efficiency (i.e. $\mathcal{P}_{H P P}=\alpha_{2} \mathcal{P}_{\mathrm{dc}}=\left(1-\alpha_{1}\right) \mathcal{P}_{\mathrm{dc}}$, in case of $\left.n=2\right)$. This, advantageously leads to increase the freshwater 
production. On the opposite case with higher $\alpha_{1}$ values, WP efficiency can be improved and the brackish water level in the tank increases accordingly. This enables to increase the storage amount of brackish water in the tank for later use by the RO process when the renewable energy is available. It is also possible to simultaneously store brackish water in the tank and produce freshwater when the renewable energy is abundant (i.e. very high generated power supply). Therefore, the generated power from renewable sources is strongly coupled with the water process system efficiency: in particular, the importance of respecting pumping power limits as defined in (17) is put forward to prevent problematic operations that degrade efficiency and could also reduce the lifetime of pumps. The latter issue emphasizes the first coupling between "power and subsystems efficiency".

On the other hand, EMS performance is affected when modifying the sizing of motor-pumps. It depends on the choice of the motor-pump rated power: here respectively $(0.75 \mathrm{~kW}$ and $2.2 \mathrm{~kW})$ as initial combination in the desalination system, then $(0.37 \mathrm{~kW}$ and $2.2 \mathrm{~kW})$ as a second combination. Indeed, by choosing another motorpump with lower rated power, but with relatively high flow rate, energy efficiency of the motor-pump can be relatively improved with a lower power consumption $\mathcal{P}_{p i}$. Consequently, EMS performance will be influenced. This issue emphasizes the second coupling between "sizing and management performance".

A third coupling between "tank level and power management" has to be managed. Indeed, after a certain operation time of the WP(s), the maximum filling level of the tank $T_{1}$ can be attained and subsequently WPs must be shut down. On the other hand, operating the HPP is only possible if the tank $T_{1}$ is not empty.

Based on this strongly coupled system design (water management and pump sizing), a Deterministic Rule-based EMS is developed. It consists of deterministic energy dispatch that evaluates the system states of the desalination system based on set rules, then computes the respective energy dispatches.

It should be noted that the experimental desalination test bench installed in our research laboratory (L.S.E in ENIT-UTM, Tunis, Tunisia) presents a prototype including two pumping devices: one WP and one HPP. Indeed, the experimental test bench is exploited for two sizing steps: the first sizing is $0.75 \mathrm{~kW}$ for well pumping and $2.2 \mathrm{~kW}$ for the RO process, and the second sizing is respectively $0.37 \mathrm{~kW}$ and $2.2 \mathrm{~kW}$ whose characteristics are reported in Table 2. It is a simplified case study, but the methodology may be extrapolated to any number of subsystems. In this work, it can be extrapolated to three pumping devices: two parallel WPs functioning through exploiting pumps modularity versus the input power, and one HPP. So, in the next subsection the influence of both "pump sizing" and "modularity" on management performance are investigated and analyzed.

In this work, the suitable power range $\left[\mathcal{P}_{\min }-\mathcal{P}_{\max }\right]$ of each pumping device has been experimentally identified (for more details see ref. [51]) while functioning with a given hydraulic load.

\subsection{Rule-based EMS}

According to the given power $\mathcal{P}_{\mathrm{dc}}$, and given the hydraulic loads characteristics, a modular approach (i.e. several motor-pumps that can be switched on/off and tuned) for energy management is applied to the studied system. This management approach is based on different operating modes that can be switched during the system operation. Indeed, from the power ranges of motor-pumps, three main operating modes are considered and explained in Table 4. The operating mode preference essentially depends on: $i$ ) the given power supply $\left.\mathcal{P}_{\mathrm{dc}}, i i\right)$ the stored water level $L$ in the tank $T_{1}$ that must vary on its specified confines ( $L_{\min }{ }^{\text {Inf }} \leq L \leq L_{\max }{ }^{\text {Sup }}$ ), and iii) the operating power range of each pumping device $\left[\mathcal{P}_{\min }-\mathcal{P}_{\max }\right]$. 
Table 4 The possible operating modes of the BWRO desalination system

\begin{tabular}{|c|c|}
\hline Operating mode & Description \\
\hline Mode P & $\begin{array}{l}\text { Pumping mode: at least one WP is switched } \\
\text { On, the HPP is shut down. During this mode, } \\
\text { pumped brackish water (to be traited) is } \\
\text { stored in the tank } T_{1} \text {. }\end{array}$ \\
\hline Mode D & $\begin{array}{l}\text { Deslination mode: all WPs are shut down } \\
\text { and the HPP is switched On. During this } \\
\text { mode, the stored brackish water in the tank is } \\
\text { exploited to produce freshwater. }\end{array}$ \\
\hline Mode P\&D & $\begin{array}{l}\text { 'Pumping and Desalination' mode: the HPP } \\
\text { and at least one WP are switched On. This } \\
\text { mode is recommended when the genrated } \\
\text { power is abundant. }\end{array}$ \\
\hline Mode OFF & The system is shut down. \\
\hline
\end{tabular}

Regarding the storage tank $T_{1}$, four limit levels ( $L_{\min }{ }^{\operatorname{Inf}}, L_{\min }{ }^{\text {Sup }}, L_{\max }{ }^{\operatorname{Inf}}, L_{\max }{ }^{\text {Sup }}$ ) are defined in this study. The idea of choosing such boundaries is to maintain the tank filling state within an acceptable range $\left[L_{\min }{ }^{\text {Sup }}-L_{\max }{ }^{\operatorname{Inf}}\right]$. Moreover, each limit interval ([ $\left.\left.L_{\min }{ }^{\text {Inf }}-L_{\min }{ }^{\text {Sup }}\right],\left[L_{\max }{ }^{\text {Inf }}-L_{\max }{ }^{\text {Sup }}\right]\right)$ permits to avoid respectively the tank emptying and overflow. These intervals make a "safety margin" against the successive occurrence of motorpumps-switched On/Off. For example, within the $\left[L_{\min }{ }^{\operatorname{Inf}}-L_{\min }{ }^{\text {Sup }}\right]$ margin the HPP must be shut down in order to avoid emptying the tank and only the WP should operate to increase the water level if the renewable power is available. This may avoid the successive HPP-switched On/Off. The opposite case is considered for the $\left[L_{\max }{ }^{\operatorname{Inf}}-\right.$ $\left.L_{\max }{ }^{\text {Sup }}\right]$ margin.

In order to study the influence of pump sizing and modularity on management performance, four pump combinations are proposed that are summarized in Table 5 and corresponding operating ranges are illustrated in Fig.9. For example, for Comb.3 where the $\mathrm{WP}_{1}, \mathrm{WP}_{2}$ and $\mathrm{HPP}$ are used, three different power ranges have to be considered in the energy management that are respectively as follows: [120W-1020W], [120W-370W] and [620W-1800W]. Three additional limits are also added which are as follows: $(2170 \mathrm{~W}=370 \mathrm{~W}+1800 \mathrm{~W})$, $(2820 \mathrm{~W}=1020 \mathrm{~W}+1800 \mathrm{~W})$, and $(3190 \mathrm{~W}=370 \mathrm{~W}+1020 \mathrm{~W}+1800 \mathrm{~W})$. As a result, nine power intervals are obtained to be tested on the input generated power $\mathcal{P}_{\mathrm{dc}}$ in the rule-based power sharing algorithm. So, the decision making for power sharing depends on the $\mathcal{P}_{\mathrm{dc}}$ value and the filling state of the storage tank as depicted in Fig.9. For example, if $\left(\mathcal{P}_{\mathrm{dc}}=700 \mathrm{~W} \in[620 \mathrm{~W}-1020 \mathrm{~W}]\right)$ and $\left(L_{\min } \sup <L<L_{\text {intermed }}\right)$ then $\left(\alpha_{1}=1, \alpha_{2}=0\right.$ and $\left.\alpha_{3}=0\right)$. That means that the $\mathrm{WP}_{1}$ is set $\mathrm{On}\left(\right.$ i.e. $\mathcal{P}_{W P 1}=\mathcal{P}_{\mathrm{dc}}$ ), and the $\left\{\mathrm{WP}_{2}\right.$ and HPP $\}$ are shut down (i.e. $\mathcal{P}_{W P 2}=\mathcal{P}_{H P \mathrm{P}}=0$ ). In this case, the system takes benefit of the total generated power to operate only in pumping mode in order to increase the brackish water storage amount in the tank. When the generated power increases (e.g. $\left.\mathcal{P}_{\mathrm{dc}}=1000 \mathrm{~W}\right)$ and the brackish water level exceeds the intermediate level (i.e. $\left.L>L_{\text {intermed }}\right)$, then $\left(\alpha_{1}=0, \alpha_{2}=0\right.$ and $\left.\alpha_{3}=1\right)$. In this case, the system operates only in desalination mode (i.e. $\mathcal{P}_{H P P}=\mathcal{P}_{\mathrm{dc}}$ ) to produce freshwater and the well pumps are both shut down (i.e. $\mathcal{P}_{W P 1}=\mathcal{P}_{W P 2}=0$ ).

400 According to the different pump-combinations four different Deterministic Rule-based algorithms are developed and tested for energy management. One example of the developed rule-based algorithms is described through the flowchart depicted in Fig.10 giving an idea on the mode preference according to the input power and the current water level in the tank. Indeed, the presented algorithm offers several degrees of freedom permitting to optimize the different pumps operation, namely: for the input electrical power by defining thresholds $\left(\mathcal{P}_{W P}{ }^{\min }, \mathcal{P}_{W P}{ }^{\max }\right.$, 
$\left.\mathcal{P}_{H P P}{ }^{\min }, \mathcal{P}_{H P P}{ }^{\max }, \mathcal{P}_{\max }=\mathcal{P}_{W P}^{\max }+\mathcal{P}_{H P P^{\max }}\right)$, and for the storage tank by defining thresholds $\left(L_{\min }{ }^{\text {Inf }}, L_{\min }{ }^{\text {Sup }}, L_{\text {intermed }}\right.$,

$L_{\max }{ }^{\mathrm{Inf}}, L_{\max }{ }^{\text {Sup }}$. The intermediate level defined by (19) is a supplementary threshold limit defining the power dispatching strategy. So, as illustrated in Fig.9 under this level ( $\left.L \leq L_{\text {intermed }}\right)$, the priority is addressed to the well pumping (brackish water storage) over the desalination process so that $\mathrm{WP}(\mathrm{s})$ can function as much as possible to fill the storage tank. In addition, when the renewable energy is abundant, it is possible to operate simultaneously the two processes while ensuring that: $Q_{W P} \geq Q_{H P P}$ in order to prevent emptying the tank. In this case, the system operates in pumping mode with "desalination mode in a moderate way". On the opposite, when $L>L_{\text {intermed }}$ there is enough stored brackish water. This enables to switch the priority to the desalination process over well pumping leading to maximize the freshwater production. In addition to that, when the renewable energy is abundant both processes can operate simultaneously while ensuring that: $Q_{W P} \leq Q_{H P P}$ in order to prevent tank overflow. In this case, the system operates in desalination mode with "pumping mode in a moderate way". This strategy is implemented and described through the flowchart of one developed EMS that is illustrated in Fig.10.

$$
L_{\text {intermed }}=\frac{L_{\min }^{\mathrm{Inf}}+L_{\max }^{\mathrm{Sup}}}{2}\left(\frac{Q_{H P P}}{Q_{W P}}\right)
$$

Table 5 Different pump combinations

\begin{tabular}{lllll}
\hline \hline & Comb.1 & Comb.2 & Comb.3 & Comb.4 \\
\hline Pump combination & $\mathrm{WP}_{1} / \mathrm{HPP}$ & $\mathrm{WP}_{2} / \mathrm{HPP}$ & $\mathrm{WP}_{1} / \mathrm{WP}_{2} / \mathrm{HPP}$ & $\mathrm{WP}_{2} / \mathrm{WP}_{2} / \mathrm{HPP}$ \\
& $(0.75 / 2.2 \mathrm{KW})$ & $(0.37 / 2.2 \mathrm{KW})$ & $(0.75 / 0.37 / 2.2 \mathrm{KW})$ & $(0.37 / 0.37 / 2.2 \mathrm{KW})$ \\
\hline \hline
\end{tabular}

Note that the flow rate $Q_{p i}$ of the $i^{\text {th }}$ pump is computed by inverting the expression (13) and using the reference feed power value of the $i^{\text {th }}$ pump calculated by (15). The task here is to compute the instantaneous values of the $\alpha_{i}$ factor enabling to reach the sought objective of EMS. Simulation results are analyzed in the next section. 


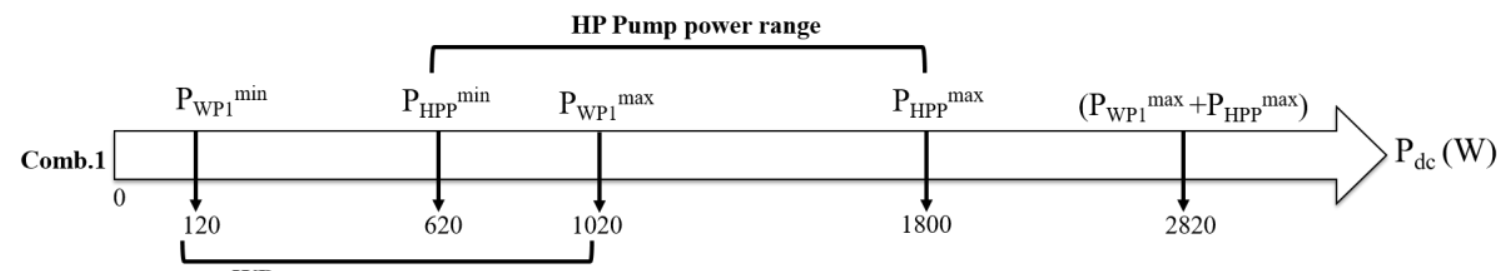

$\mathrm{WP}_{1}$ power range
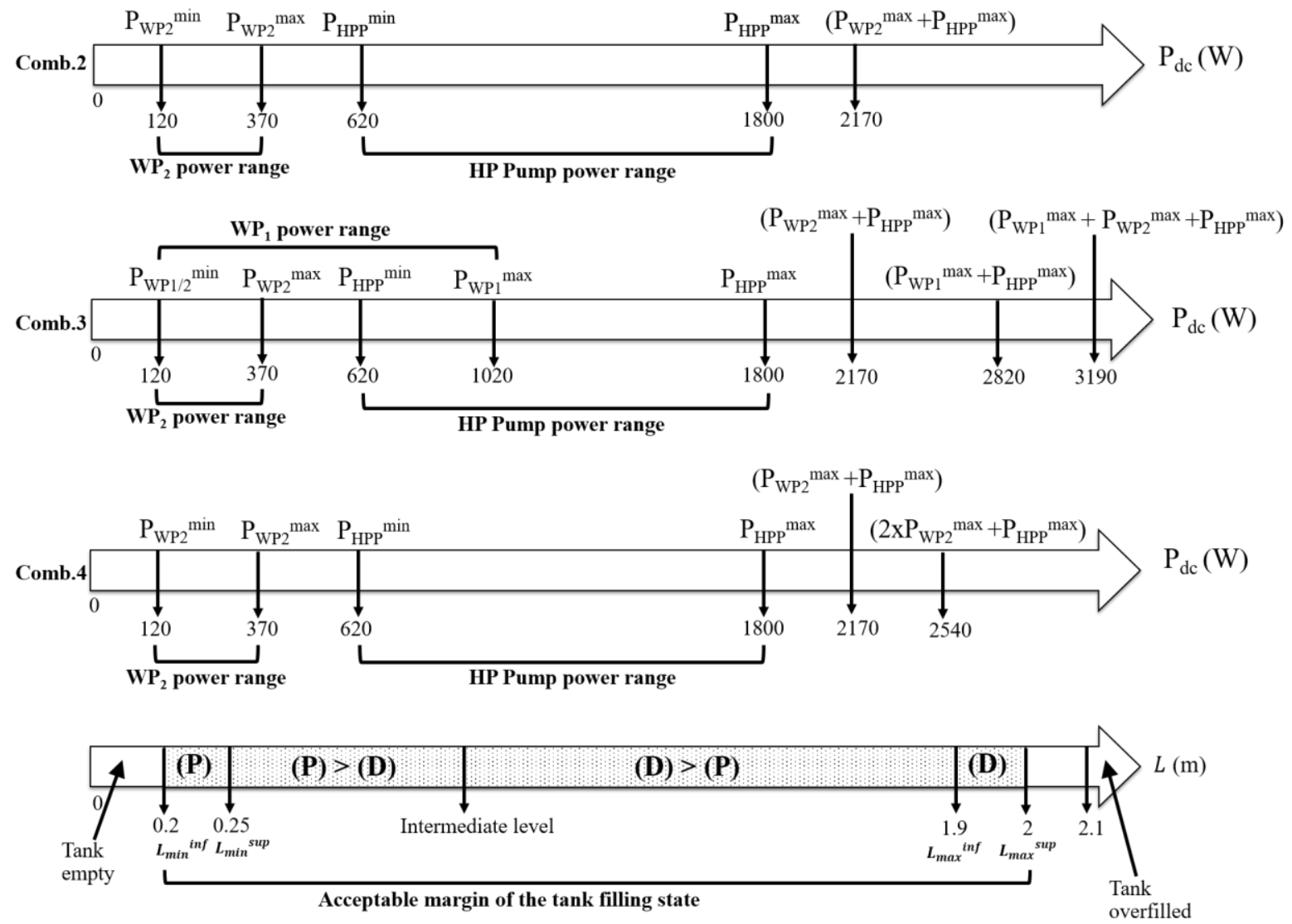

(P) $>$ (D) : favoring Pumping (P) over Desalination (D) mode

(D) $>$ (P) : favoring Desalination (D) over Pumping (P) mode

Fig.9. Power ranges for different pump combinations with operating mode preference according the stored water level 


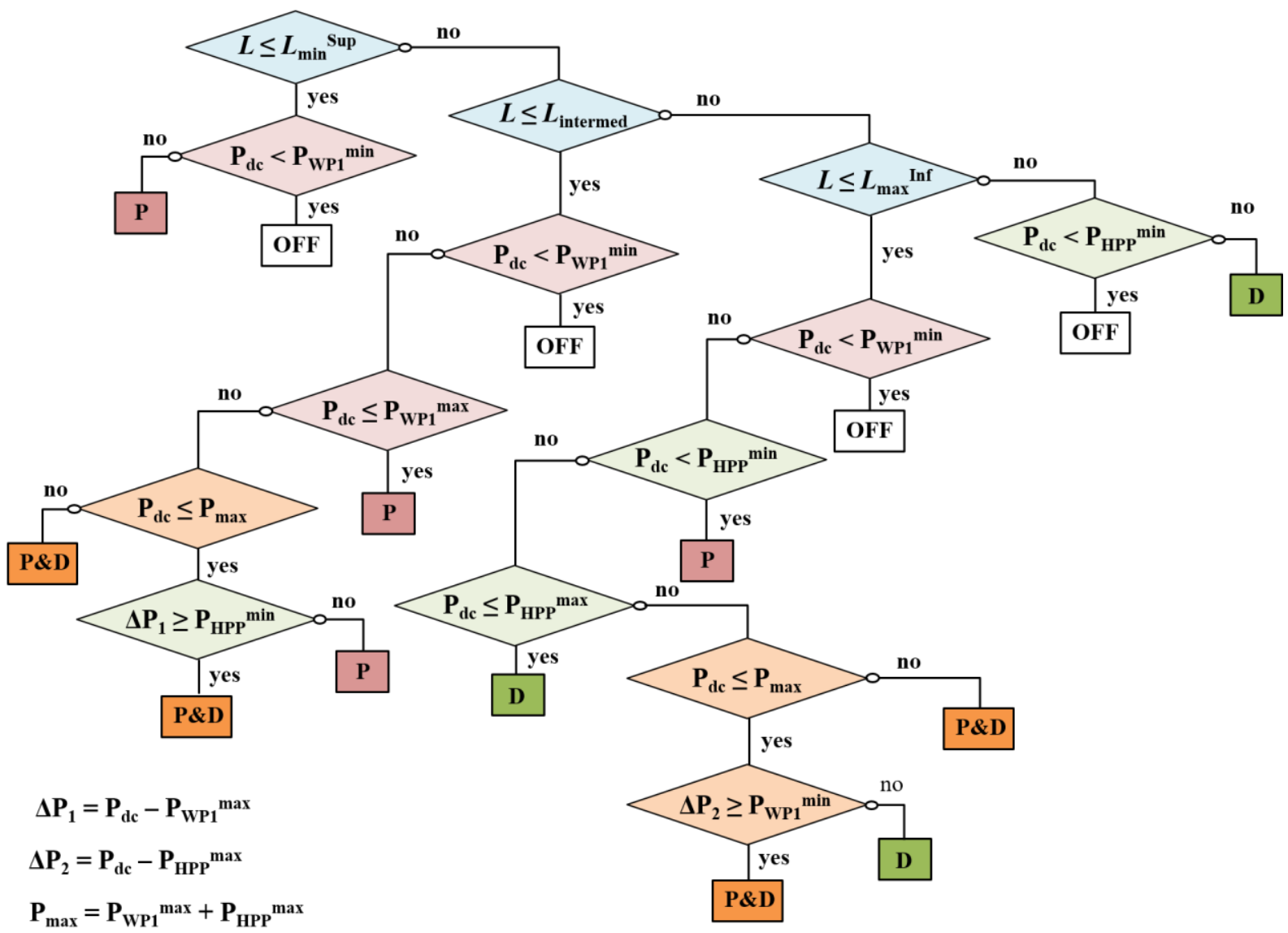

Fig.10. Flowchart of the Deterministc Rule-based energy management strategy for Comb.1

\section{Simulation results analysis}

This section is dedicated to analyze the EMS performance through simulations where different components sizing and different pump-combinations are considered.

The simulations have been accomplished using real data of hybrid PV/Wind power generation recorded every hour from January to December, 2007 of a region in Southeast Tunisia: Djerba-Midoun. The PV source is composed of 8 monocrystalline modules (from elysun) of $250 \mathrm{Wp}$ each, where the total generated power is of $2 \mathrm{kWp}$. As for the wind turbine source, the Aeolos- $2 \mathrm{~kW}$ wind turbine is used with rated power of $2 \mathrm{~kW}$.

The different dispatch algorithms have been coded under $\mathrm{Matlab}^{\odot}$ software using the simulation parameters reported in Table 6 where the considered sampling period is 2.5 minutes (i.e. the sampling period is $T_{s}=2.5 \times 60$ $=150 \mathrm{~s}$ ). Indeed, an interpolation has been performed on the recorded hourly power profile in order to modify the sampling period $\left(T_{s}=1 \mathrm{~h}\right)$ which represents a long time interval for the proposed EMS. A daily and weekly power profiles, depicted in Fig.11, were considered for tests and analysis. It should be noted that during simulations two RO membranes have been considered.

Table 6 Simulation parameters

\begin{tabular}{llll}
\hline \hline Symbol & Description & Value & Unit \\
\hline$k_{1}$ & Number of samples in a day & 553 & samples \\
$k_{2}$ & Number of samples in a week & 4009 & samples \\
$k_{3}$ & Number of samples in a year & 210217 & samples \\
$T_{\mathrm{s}}$ & Sampling period & 150 & $\mathrm{~s}$ \\
$T_{\mathrm{t}}$ & Total time for one day & 82950 & $\mathrm{~s}$ \\
$F S_{\max }$ & Maximum Filling State of the tank & 100 & $\%$ \\
$F S_{\min }$ & Minimum Filling State of the tank & 10 & $\%$ \\
$F S_{0}$ & Initial Filling State of the tank & 60 & $\%$ \\
\hline
\end{tabular}




\begin{tabular}{|c|c|c|c|}
\hline $\mathcal{P}_{H P P} \min$ & Minimum power of HPP & 620 & W \\
\hline $\mathcal{P}_{H P P}{ }^{\max }$ & Maximum power of HPP & 1800 & W \\
\hline $\mathcal{P}_{W P 1}{ }^{\min }$ & Minimum power of $\mathrm{WP}_{1}$ & 120 & W \\
\hline $\mathcal{P}_{W P 1}{ }^{\max }$ & Maximum power of $\mathrm{WP}_{1}$ & 1020 & W \\
\hline $\mathcal{P}_{W P 2}{ }^{\min }$ & Minimum power of $\mathrm{WP}_{2}$ & 120 & W \\
\hline $\mathcal{P}_{W P 2}{ }^{\max }$ & Maximum power of $\mathrm{WP}_{2}$ & 370 & W \\
\hline $\mathcal{P}_{\mathrm{dc}}^{\max }$ & Maximum generated DC power & 4000 & W \\
\hline
\end{tabular}

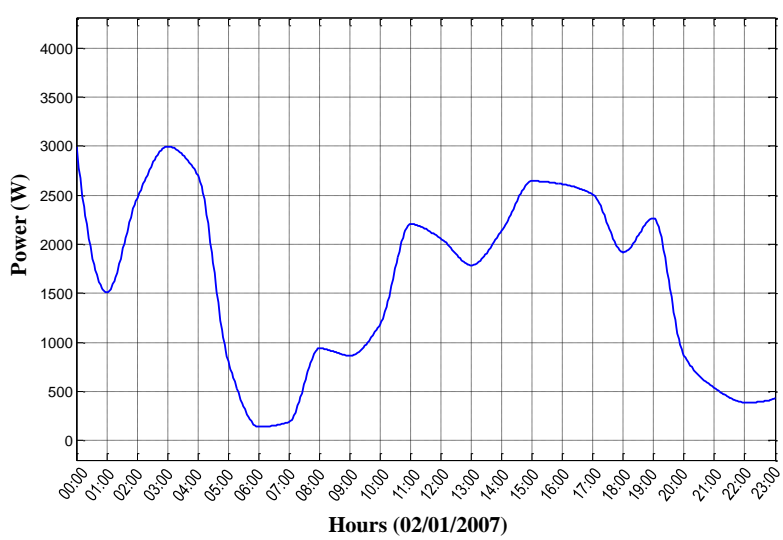

(a)

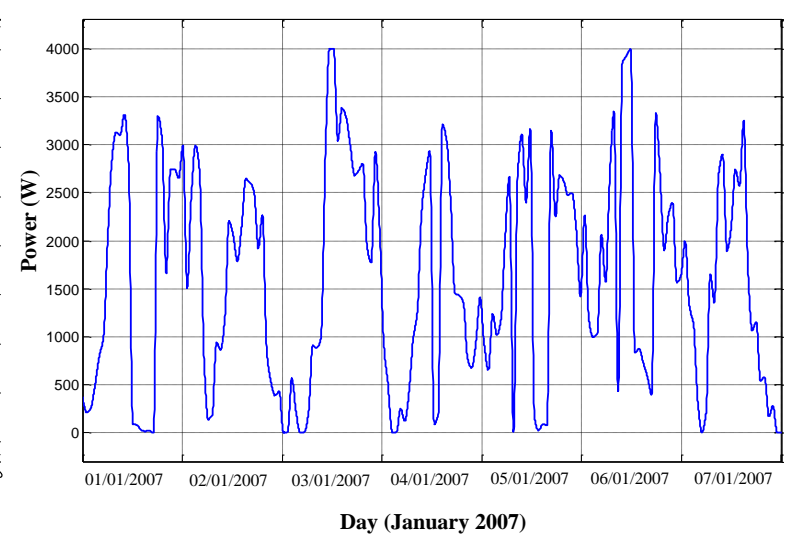

(b)

Fig.11. Daily (a) and weekly (b) PV-Wind generated electrical power profiles

Results of the developed EMS for each pump combination are reported in Table 7. These results are assessed in terms of freshwater production $q_{\text {fresh }}\left(\mathrm{in}^{3}\right.$ ) for the two presented power profiles. As it is previously explained, the main objective of the EMS is to maximize as much as possible the freshwater production while taking benefit of the available renewable energy. This permits to increase as much as possible the freshwater amount storage that will be used later when renewable energy is unavailable. In such a way, electrochemical storage device can be avoided. According to this criterion, best results (i.e. the higher produced freshwater amount) are indicated in bold type in Table 7. It can be deduced from this table that the most appropriate combination in terms of freshwater production is Comb. 4 where two parallel identical well pumps with a rated power of $0.37 \mathrm{~kW}$ each are used for the welling process. The pump modularity approach is applied here; according to the generated input power level the well pumping process can operate either a single pump $(0.37 \mathrm{~kW})$, or simultaneously the two parallel pumps where the input power is shared between them. This approach has the advantage of operating only one pump $\mathrm{WP}_{2}$ with lower rated power $(0.37 \mathrm{~kW})$, but with higher energy efficiency when the given input power is very low compared with the single pump $\mathrm{WP}_{1}(0.75 \mathrm{~kW})$. Then, when the input power level rises, the modularity approach offers the possibility to operate simultaneously more than one pump operating each with good energy efficiency.

Moreover, the influence of HPP sizing on the system efficiency is also analyzed: so the previously used HPP (EBARA EVM2 22F/2.2) is substituted now by a new HPP (rated power of $1.5 \mathrm{~kW}$ instead of $2.2 \mathrm{~kW}$ ) and used for all previous pump combinations. The new HPP, where characteristics are reported in Table 8, was selected from the Grundfos manufacturer's catalog. Its electrical and hydraulic characteristic curves were taken from the Grundfos Product Center, an online tool proposed by Grundfos for the research and design of pumps. Simulation results for the different pump combinations with the new HPP are reported in Table 9. For the sake of visibility, the obtained results are illustrated in Fig.12 and Fig.13 where changes on the freshwater amounts are more visualized. It is noticed that the freshwater production is improved when using the new HPP whose rated power is lower than the first one, but with higher energy yield.

Table 7 Produced freshwater quantity (in $\mathrm{m}^{3}$ ) according to component sizing

$\begin{array}{llll}\text { Comb.1 } & \text { Comb. } 2 & \text { Comb.3 } & \text { Comb.4 }\end{array}$




\begin{tabular}{|c|c|c|c|c|}
\hline \multicolumn{5}{|c|}{ Storage tank $T_{1}$ capacity $\mathrm{C} 1: 2.18 \mathrm{~m}^{3}$} \\
\hline Daily power profile & 11.96 & 11.86 & 11.95 & 12.03 \\
\hline Weekly power profile & 78.47 & 78.93 & 78.86 & 79.35 \\
\hline \multicolumn{5}{|c|}{ Storage tank $T_{1}$ capacity C2: $4.36 \mathrm{~m}^{3}$} \\
\hline Daily power profile & 12.12 & 12.06 & 12.12 & 12.2 \\
\hline Weekly power profile & 80.46 & 80.45 & 80.68 & 80.88 \\
\hline
\end{tabular}

Table 8 Characteristics of the new HPP Grundfos 1.5kW - CRE 1-21

\begin{tabular}{lll}
\hline \hline Components & Characteristics & Component constraints \\
\hline Grundfos HPP & Model: CRE 1-21 & Minimum absorbed electric power: $596 \mathrm{~W}$ \\
& Type: centrifugal pump & Maximum absorbed electric power: $1563 \mathrm{~W}$ \\
& Power output: $1.5 \mathrm{~kW}$ & \\
& Rated Pressure: $7.7-18 \mathrm{bar}$ & \\
& Rated flow rate: $13.3-46.6 \mathrm{l} / \mathrm{min}$ & \\
\hline \hline
\end{tabular}

On the other hand, besides to the influence of pump sizing, the influence of the brackish water storage tank sizing (capacities $\mathrm{C} 1$ and $\mathrm{C} 2$ ) on the management performance is also investigated by doubling the tank capacity $\left(\mathrm{C} 2=4.36 \mathrm{~m}^{3}\right)$. As it can be seen in Table 7, Table 9, Fig.12 and Fig.13 when doubling the hydraulic storage capacity, the freshwater production is improved for all combinations. This means that increasing the hydraulic storage capacity enables to improve the system productivity and the renewable energy use. The later in turn could play an important role in the energy optimization. In addition to that, Comb.4 is always still the most appropriate combination in terms of freshwater production, especially when using the new HPP (1.5kW - CRE 1-21).

All of the above mentioned findings highlight the great importance of:

- The strongly coupling between "the power and subsystems efficiency", and coupling between "the pump sizing and the energy management performance".

- The strongly coupling between "water management and pump sizing”.

\begin{tabular}{lcccc}
\hline \hline \multicolumn{1}{c}{ Comb.1 } & Comb.2 & Comb.3 & Comb.4 \\
\hline Storage tank $T_{1}$ capacity $\mathrm{C} 1: 2.18 \mathrm{~m}^{3}$ & & & \\
Daily power profile & 12.05 & 11.97 & 12.07 & $\mathbf{1 2 . 1}$ \\
Weekly power profile & 79.5 & 79.82 & 79.95 & $\mathbf{8 0 . 2 4}$ \\
Storage tank $T_{1}$ capacity & $\mathrm{C} 2: 4.36 \mathrm{~m}^{3}$ & & & \\
Daily power profile & 12.31 & 12.28 & 12.35 & $\mathbf{1 2 . 3 4}$ \\
Weekly power profile & 81.74 & 81.56 & 82.04 & $\mathbf{8 2 . 1 2}$ \\
\hline \hline
\end{tabular}




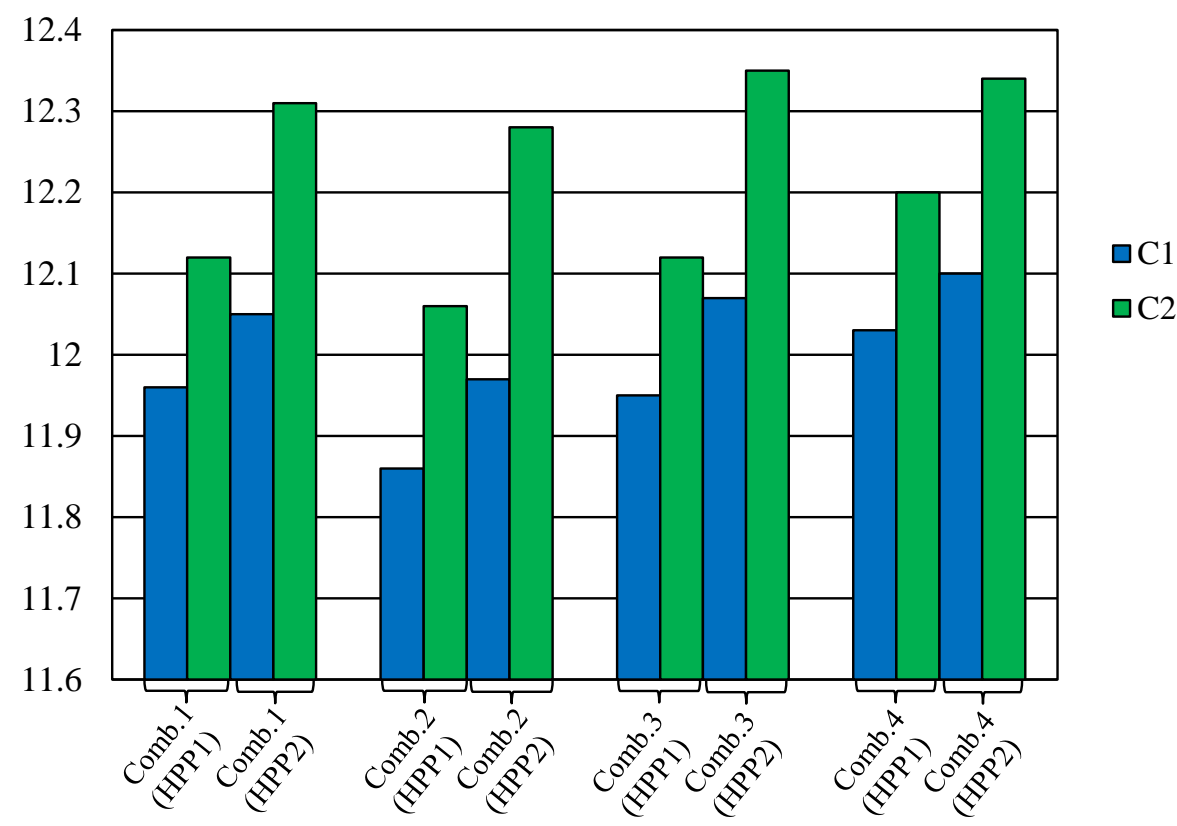

Fig.12. Produced freshwater quantity (in $\mathrm{m}^{3}$ ) for the different pump-combinations for a daily power profile.

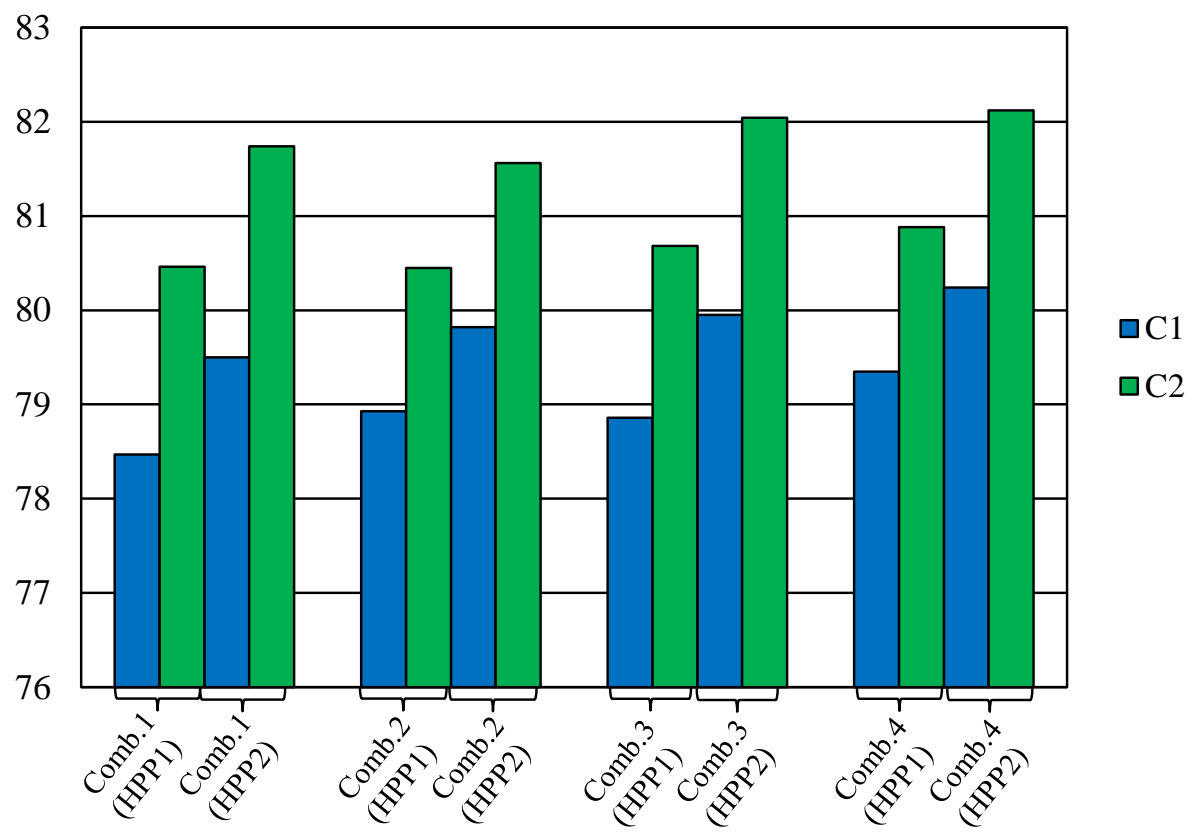

Fig.13. Produced freshwater quantity (in $\mathrm{m}^{3}$ ) for the different pump-combinations for a weekly power profile.

It should be pointed out that designing the desalination system based on the modularity approach is advantageous for non-expert small communities enabling them to easily configure such a desalination unit. In such a case the system becomes flexible and is assembled from modular components such as motor-pumps, RO membranes and even the solar PV modules. So, non-experts have the possibility to reduce or extend in a second step the number of these modular components according to the community demand. This can reduce the capital cost, and makes its maintenance and repair tasks simpler and easier than conventional design approaches.

The adopted concept of storing the generated renewable energy during sunny and/or windy days in the form of water offers a simple, very cost-effective and environmentally friendly alternative, especially for small-scale desalination units. Nonetheless, this solution does not deal with the impact of frequent system shutdown or successive On/Off cycling of motor-pumps that may occur. Generally, this may increase the potential wear on 
motor-pumps and reduce their lifetime. For this purpose, the systemic design approach is applied in this work to investigate the suitable pump combination and sizing according to both the chosen architecture and the available renewable energy, in one-side. Indeed, this approach puts forward the strong coupling between the renewable generated power and the water process system efficiency, and coupling between device sizing (especially motorpumps) and energy management performance. Such a design approach can help to reduce the non-recommended successive On/Off cycling of motor-pumps and the frequent system shutdown. In the other-side, the proposed power sharing algorithm is developed so that successive On/Off of motor-pumps is minimized following the available PV/Wind generated power. This is achieved by including supplementary level limits $\left(L_{\text {intermed, }} L_{\text {min }}{ }^{\text {Inf }}\right.$, $L_{\min }{ }^{\text {Sup }}, L_{\max }{ }^{\text {Inf }}, L_{\max }$ Sup ) on the brackish water storage tank $T_{1}$. The idea is to operate the pump in a moderate way rather than setting it Off in some level intervals, and favoring single-pump operation rather than multi-pump operation in other level intervals making a safety margin against the successive occurrence of pumps-switched On/Off. Besides to the deterministic rules, fuzzy logic is also a useful tool that can be used in the energy management for this sake. For example, a genetic algorithm optimized fuzzy logic-based energy management strategy was previously developed by authors (ref. [51]) and applied to the first pump combination Comb.1 of the desalination unit with a storage tank capacity of $2.18 \mathrm{~m}^{3}$. This helps to reduce the number of successive On/Off of motor-pumps.

\section{Conclusion}

This work is within the context of complex energy system design. The principle of the adopted systemic design approach is to start from component system characterization, going through the modeling phase, to achieve an efficient energy management in real-time. In this regard, the system architecture was defined so that continuously freshwater productivity and supply are insured while taking into account the environmental and capital cost issues. This is achieved by means of integrating hydraulic storage (brackish water and freshwater) in water tanks when renewable energy is available instead of electrochemical storage device; the available renewable energy can be stored in the form of water. This is very advantageous and cost-effective in terms of energy storage. An experimental BWRO desalination test bench at the laboratory scale has been installed by authors according to the defined system architecture. It is considered as a prototype in order to investigate the feasibility and reliability of such autonomous desalination system in rural and poverty region for drinking and/or agriculture. The different hydraulic processes were previously experimentally characterized. Based on both previous experimental study and dynamic modelling, a quasi-static model of the whole desalination system was carried out and presented in this work for simulations and performance analysis. Then, a deterministic rule-based energy management strategy (EMS) was defined enabling to manage simultaneously the water and power flows into the system. The EMS was developed so that freshwater production is maximized according to the available generated power while fulfilling the technical and functional constraints of the system. Maximizing the system productivity and storing freshwater is beneficial from a continuous water supply perspective, especially when renewable energy is not available. For the sake of system design optimality, the influence of the component sizing (pumps and tank capacity) on the system efficiency and the energy management performance were investigated and analyzed in this work. Several pumps sizing and combinations for two different capacities of the brackish water storage tank are proposed. It was demonstrated that there is a strong coupling between "power and system efficiency", a coupling between "sizing and management performance", and also a third coupling between "tank level and power management". All of these couplings and their interrelationships are defined within the so-called systemic design approach. 
Simulation results showed that by applying the modularity approach, the most convenient components sizing corresponds to the motor-pumps of lower rated powers, but offering higher energy efficiencies compared to those of higher rated powers. The same observation was noticed when increasing the capacity of the brackish water storage tank. These findings demonstrated that the available renewable energy use can be optimized and the freshwater production can be maximized by choosing the convenient system architecture and the optimized components sizing, highly correlated with the energy management strategy.

Another issue was highlighted in this work related to the influence of the successive switching On/Off of motorpumps on their lifetime. The adopted systemic design approach with the defined system architecture and the developed EMS enabled to initially reduce the number of pumps-switching On/Off events. However, this issue has to be addressed with the greatest accuracy. For instance, renewable energy forecast can be a viable solution to predict renewable power generation for the next time intervals. This enables to significantly improve the energy management performance while taking into consideration the constraint of motor-pumps lifetime by reducing the number of pumps-switching On/Off events.

All of these findings justify a deep and more sophisticated study to investigate global optimization approaches taking account of the couplings between the system architecture, sizing and energy management, while respecting the different system constraints.

\section{Acknowledgment}

This work was supported by the Tunisian Ministry of Higher Education and Research under Grant LSE-ENIT-LR $11 E S 15$ and the European project "ERANETMED - EDGWISE" ID 044".

\section{References}

[1] L.F. Greenlee, D.F. Lawler, B.D. Freeman, B. Marrot, and P. Moulin, "Reverse osmosis desalination: water sources, technology, and today's challenges," Water Research, vol. 43, no. 9, pp. 2317-2348, May 2009. https://doi.org/10.1016/j.watres.2009.03.010.

[2] N. Ghaffour, T.M. Missimer, and G.L. Amy, "Technical review and evaluation of the economics of water desalination: Current and future challenges for better water supply sustainability,” Desalination, vol. 309, pp. 197-207, January 2013. https://doi.org/10.1016/j.desal.2012.10.015.

[3] S. Burn, M. Hoang, D. Zarzo, F. Olewniak, E. Campos, B. Bolto, and O. Barron, "Desalination techniques - A review of the opportunities for desalination in agriculture,”, Desalination, vol. 364, pp. 2-16, May 2015. https://doi.org/10.1016/j.desal.2015.01.041.

[4] K. Bourouni, T.B. MBarek, and A. Al Taee, "Design and optimization of desalination reverse osmosis plants driven by renewable energies using genetic algorithms," Renewable Energy, vol. 36, no. 3, pp. 936-950, March 2011. https://doi.org/10.1016/j.renene.2010.08.039.

[5] A. Ali, R.A. Tufa, F. Macedonio, E. Curcio, and E. Drioli, "Membrane technology in renewable-energy-driven desalination," Renewable and Sustainable Energy Reviews, vol. 81, pp. 1-21, January 2018. https://doi.org/10.1016/j.rser.2017.07.047.

[6] M.A. Abdelkareem, M. El Haj Assad, E.T. Sayed, and B. Soudan, "Recent progress in the use of renewable energy sources to power water desalination plants," Desalination, vol. 435, pp. 97-113, June 2018. https://doi.org/10.1016/j.desal.2017.11.018.

[7] F.E. Ahmed, R. Hashaikeh, and N. Hila, "Solar powered desalination - Technology, energy and future outlook," Desalination, vol. 453, pp. 54-76, March 2019. https://doi.org/10.1016/j.desal.2018.12.002.

[8] A. Ghafoor, T. Ahmed, A. Munir, Ch. Arslan, and S.A. Ahmad, "Techno-economic feasibility of solar based desalination through reverse osmosis," Desalination, vol. 485, July 2020. https://doi.org/10.1016/j.desal.2020.114464.

[9] S. Loutatidou, N. Liosis, R. Pohl, T.B.M.J. Ouarda, and H.A. Arafat, "Wind-powered desalination for strategic water storage: Technoeconomic assessment of concept,” Desalination, vol. 408, pp. 36-51, April 2017. https://doi.org/10.1016/j.desal.2017.01.002.

[10] M.A.M. Khan, S. Rehman, and F.A. Al-Sulaiman, "A hybrid renewable energy system as a potential energy source for water desalination using reverse osmosis: A review,” Renewable and Sustainable Energy Reviews, vol. 97, pp. 456-477, December 2018. https://doi.org/10.1016/j.rser.2018.08.049. 
[11] N. Ghaffour, J. Bundschuh, H. Mahmoudi, and M.F.A. Goosen, "Renewable energy-driven desalination technologies: A comprehensive review on challenges and potential applications of integrated systems," Desalination, vol. 356, pp. 94-114, January 2015. https://doi.org/10.1016/j.desal.2014.10.024.

[12] J. Jurasza, F.A. Canales, A. Kies, M. Guezgouz, and A. Beluco, "A review on the complementarity of renewable energy sources: Concept, metrics, application and future research directions," Solar Energy, vol. 195, pp. 703-724, January 2020. https://doi.org/10.1016/j.solener.2019.11.087.

[13] A. Soric, R. Cesaro, P. Perez, E. Guiol, and P. Moulin, "Eausmose project desalination by reverse osmosis and batteryless solar energy: Design for a $1 \mathrm{~m}^{3}$ per day delivery," Desalination, vol. 301, pp. 67-74, September 2012. https://doi.org/10.1016/j.desal.2012.06.013.

[14] D.P. Clarke, Y.M. Al-Abdeli, G. Kothapalli, "Multi-objective optimization of renewable hybrid energy systems with desalination," Energy, vol. 88, pp. 457-468, August 2015. https://doi.org/10.1016/j.energy.2015.05.065.

[15] A. Maleki, F. Pourfayaz, and M.H. Ahmadi, "Design of a cost-effective wind/photovoltaic/hydrogen energy system for supplying a desalination unit by a heuristic approach," Solar Energy, vol. 139, pp. 666-675, December 2016. https://doi.org/10.1016/j.solener.2016.09.028.

[16] A.J.N. Khalifa, "Evaluation of different hybrid power scenarios to Reverse Osmosis (RO) desalination units in isolated areas in Iraq," Energy for Sustainable Development, vol. 15, pp. 49-54, March 2011. https://doi.org/10.1016/j.esd.2011.01.004.

[17] M. Khayet, M. Essalhi, C. Armenta-Déu, C. Cojocaru, N. Hilal, "Optimization of solar-powered reverse osmosis desalination pilot plant using response surface methodology,” Desalination, vol. 261, no. 3, pp. 284-292, October 2010. https://doi.org/10.1016/j.desal.2010.04.010.

[18] H.Ş. Aybar, J.S. Akhatov, N.R. Avezova, A.S. Halimov, "Solar powered RO desalination: investigations on pilot project of PV powered RO desalination system," Applied Solar Energy, vol. 46, no. 4, pp. 275-284, 2010. https://doi.org/10.3103/S0003701X10040080.

[19] A. Al-Karaghouli, and L.L. Kazmerski, "Economic analysis of a Brackish Water Photovoltaic-Operated (BWRO-PV) desalination system," Conference Proceeding, World Renewable Energy Congress XI, September 25-30, 2010, Abu Dhabi, United Arab Emirates. https://digitalscholarship.unlv.edu/renew_pubs/51.

[20] L.A. Richards, B.S. Richards, A.I. Schäfer, "Renewable energy powered membrane technology: Salt and inorganic contaminant removal by nanofiltration/reverse osmosis," Journal of Membrane Science, vol. 369, no. 1-2, pp. 188-195, March 2011. https://doi.org/10.1016/j.memsci.2010.11.069.

[21] H. Qiblawey, F. Banat, and Q. Al-Nasser, "Performance of reverse osmosis pilot plant powered by Photovoltaic in Jordan," Renewable Energy, vol. 36, no. 12, pp. 3452-3460, December 2011. https://doi.org/10.1016/j.renene.2011.05.026.

[22] F. Banat, H. Qiblawey, and Q. Al-Nasser, "Design and operation of small-scale photovoltaic-driven reverse osmosis (PV-RO) desalination plant for water supply in rural areas," Computational Water, Energy, and, Environmental Engineering, vol. 1, no. 3, pp. 31-36, January 2012. http://dx.doi.org/10.4236/cweee.2012.13004.

[23] F.H. Fahmy, N.M. Ahmed, H.M. Farghally, "Optimization of renewable energy power system for small scale brackish reverse osmosis desalination unit and a tourism motel in Egypt," Smart Grid and Renewable Energy, vol. 3, no. 1, pp. 43-50, January 2012. http://dx.doi.org/10.4236/sgre.2012.31006.

[24] E.M.A. Mokheimer, A.Z. Sahin, A. Al-Sharaf, and A.I. Ali, "Modeling and optimization of hybrid wind-solar-powered reverse osmosis water desalination system in Saudi Arabia," Energy Conversion and Management, vol. 75, pp. 86-97, November 2013. https://doi.org/10.1016/j.enconman.2013.06.002.

[25] A.I. Schäfer, G. Hughes, and B.S. Richards, "Renewable energy powered membrane technology: A leapfrog approach to rural water treatment in developing countries?" Renewable and Sustainable Energy Reviews, vol. 40, pp. 542-556, December 2014. https://doi.org/10.1016/j.rser.2014.07.164.

[26] S.G. Sigarchian, A. Malmquist, and T. Fransson, "Modeling and control strategy of a hybrid PV/Wind/Engine/Battery system to provide electricity and drinkable water for remote applications," Energy Procedia, vol. 57, pp. 1401-1410, 2014. https://doi.org/10.1016/j.egypro.2014.10.087.

[27] H.A. Shawky, A.A. Abdel Fatah, M.M.S. Abo ElFadl, and A.H.M. El-Aassar, "Design of a small mobile PV-driven RO water desalination plant to be deployed at the northwest coast of Egypt," Desalination and Water Treatment, vol. 55, pp. 3755-3766, 2015. https://doi.org/10.1080/19443994.2015.1080447.

[28] H. Vyas, K. Suthar, M. Chauhan, R. Jani, P. Bapat, P. Patel, B. Markam, and S. Maiti, "Modus operandi for maximizing energy efficiency and increasing permeate flux of community scale solar powered reverse osmosis systems," Energy Conversion and Management, vol. 103, pp. 94-103, October 2015. https://doi.org/10.1016/j.enconman.2015.05.076. 
[29] H. Elasaad, A. Bilton, L. Kelley, O. Duayhe, and S. Dubowsky, "Field evaluation of a community scale solar powered water purification technology: A case study of a remote Mexican community application," Desalination, vol. 375, pp. 71-80, November 2015. https://doi.org/10.1016/j.desal.2015.08.001.

[30] S. Kumarasamy, S. Narasimhan, and S. Narasimhan, "Optimal operation of battery-less solar powered reverse osmosis plant for desalination,” Desalination, vol. 375, pp. 89-99, November 2015. https://doi.org/10.1016/j.desal.2015.07.029.

[31] M. Alghoul, P. Poovanaesvaran, M. Mohammed, A. Fadhil, A. Muftah, M. Alkilani, and K. Sopian, "Design and experimental performance of brackish water reverse osmosis desalination unit powered by $2 \mathrm{~kW}$ photovoltaic system," Renewable Energy, vol. 93, pp. 101-114, August 2016. https://doi.org/10.1016/j.renene.2016.02.015.

[32] H. Bilal, A.H. Alami, M. Farooq, A. Qamar, and F.A. Siddiqui, "The Economic Analysis of Portable PhotoVoltaic Reverse Osmosis (PVRO) System,” Technical Journal, University of Engineering and Technology Taxila, vol. 21, no. 2, pp. 19-24, 2016.

[33] J. Shen, B.S. Richards, and A.I. Schäfer, "Renewable energy powered membrane technology: Case study of St. Dorcas borehole in Tanzania demonstrating fluoride removal via nanofiltration/reverse osmosis," Separation and Purification Technology, vol. 170, pp. 445-452, October 2016. https://doi.org/10.1016/j.seppur.2016.06.042.

[34] S.J. Almalowi, A.M. AlRaddadi, M.H. AlZughabi, M.M. AlHazmi, and M.H. Masoudi, "Experimental Study of Mobile Solar Reverse Osmosis for Remote Areas," Journal of Solar Energy Engineering, vol. 139, no. 6, October 2017. https://doi.org/10.1115/1.4037904.

[35] A. Maleki, "Design and optimization of autonomous solar-wind-reverse osmosis desalination systems coupling battery and hydrogen energy storage by an improved bee algorithm," Desalination, vol. 435, pp. 221-234, June 2018. https://doi.org/10.1016/j.desal.2017.05.034.

[36] S. I. Bouhadjar, H. Kopp, P. Britsch, S.A. Deowan, J. Hoinkis, and J. Bundschuh, "Solar powered nanofiltration for drinking water production from fluoride-containing groundwater - A pilot study towards developing a sustainable and low-cost treatment plant," Journal of Environmental Management, vol. 231, pp. 1263-1269, February 2019. https://doi.org/10.1016/j.jenvman.2018.07.067.

[37] M. Al-Nory, and M. El-Beltagy, “An energy management approach for renewable energy integration with power generation and water desalination,” Renewable Energy, vol. 72, pp. 377-385, December 2014. https://doi.org/10.1016/j.renene.2014.07.032.

[38] B.S. Richards, D.P.S. Capão, W.G. Früh, and A.I. Schäfer, "Renewable energy powered membrane technology: Impact of solar irradiance fluctuations on performance of a brackish water reverse osmosis system," Separation and Purification Technology, vol. 156, part 2, pp. 379-390, December 2015. https://doi.org/10.1016/j.seppur.2015.10.025.

[39] M. Freire-Gormaly and A.M. Bilton, "Experimental quantification of the effect of intermittent operation on membrane performance of solar-powered reverse osmosis desalination systems," Desalination, vol. 435, pp. 188-197, June 2018. https://doi.org/10.1016/j.desal.2017.09.013.

[40] E.S. Mohamed, G. Papadakis, E. Mathioulakisans, and V. Belessiotis, "A direct coupled photovoltaic seawater reverse osmosis desalination system toward battery based systems - a technical and economical experimental comparative study," Desalination, vol. 221, no. 1-3, pp. 17-22, March 2008. https://doi.org/10.1016/j.desal.2007.01.065.

[41] D.B. Riffel, and P.C.M. Carvalho, "Small-scale photovoltaic-powered reverse osmosis plant without batteries: design and simulation," Desalination, vol. 247, pp. 378-389, October 2009. https://doi.org/10.1016/j.desal.2008.07.019.

[42] M. Thomson, D. Infield, "Laboratory demonstration of a photovoltaic-powered seawater reverse osmosis system without batteries," Desalination, vol. 183, no. 1-3, pp. 105-111, November 2005. https://doi.org/10.1016/j.desal.2005.03.031.

[43] A.M. Bilton, L.C. Kelly, and S. Dubowsky, "Photovoltaic reverse osmosis - Feasibility and a pathway to develop technology," Desalination and Water Treatment, vol. 31, no. 1-3, pp. 24-34, 2011. https://doi.org/10.5004/dwt.2011.2398.

[44] H. Sharon, and K. Reddy, “A review of solar energy driven desalination technologies," Renewable Sustainable Energy Reviews, vol. 41, pp. 1080-1118, January 2015. https://doi.org/10.1016/j.rser.2014.09.002.

[45] Water. Desalination + Reuse, "Chile project envisions multiple mining clients for solar-powered SWRO," special report, 5 June 2017. https://www.desalination.biz/news/3/Chile-project-envisions-multiple-mining-clients-for-solar-powered-SWRO/8761/. [accessed 12 August 2020].

[46] X. Roboam, B. Sareni, T.N. Duc, and J. Belhadj, "Optimal system management of a water pumping and desalination process supplied with intermittent renewable sources,” Conference IFAC PPPSC, Toulouse, September 2012.

[47] W. Khiari, M. Turki, and J. Belhadj, "Experimental prototype of reverse osmosis desalination system powered by intermittent renewable source without electrochemical storage: Design and characterization for energy-water management," International Conference on Electrical Sciences and Technologies in Maghreb (CISTEM), Marrakesh, Morocco, 26-28 October 2016. https://doi.org/10.1109/CISTEM.2016.8066819.

[48] I. Ben Ali, M. Turki, J. Belhadj, and X. Roboam, "Systemic design of a reverse osmosis desalination process powered by hybrid energy system: Bond graph modeling approach \& experimental validation," the $1^{\text {st }}$ International Conference on Electrical Sciences and Technologies in Maghreb (CISTEM), Tunis-Tunisia, 3-6 November, 2014. https://doi.org/10.1109/CISTEM.2014.7076941. 
[49] I. Ben Ali, M. Turki, J. Belhadj, and X. Roboam, "Energy management of reverse osmosis desalination process powered by a hybrid renewable energy source," the $16^{\text {th }}$ IEEE Mediterranian Electrotechnical Conference (MELECON), Yasmine Hammamet-Tunisia, 2528 March, 2012. https://doi.org/10.1109/MELCON.2012.6196551.

[50] W. Khiari, M. Turki, and J. Belhadj, "Robust DC-bus voltage control for batteryless brackish water reverse osmosis desalination prototype operating with variable wind and solar irradiation," International Journal of Renewable Energy Research, vol. 8, no. 3, pp. 1544-1552, September 2018. https://www.ijrer.org/ijrer/index.php/ijrer/article/view/7850/pdf.

[51] I. Ben Ali, M. Turki, J. Belhadj, and X. Roboam, “Optimized Fuzzy Rule-based Energy Management for a Battery-less PV/WindBWRO Desalination System,” Energy, vol. 159, pp. 216-28, September 2018. https://doi.org/10.1016/j.energy.2018.06.110.

[52] X. Roboam, "Systemic design methodologies for electrical energy systems: analysis, synthesis and management," ebook, first published 2012 in Great Britain and the United States by ISTE Ltd and John Wiley\& Sons, Inc., pp. 28-32.

[53] J.F. Gülich, “Centrifugal Pumps,” ebook, Springer-Verlag Berlin Heidelberg, New York 2008.

[54] Grundfos research and technology, "the centrifugal pump," ebook, pp.32.

[55] M. Turki, J. Belhadj, and X. Roboam, "Bond Graph modeling and analysis of an autonomous reverse osmosis desalination process fed by a hybrid system (photovoltaic-wind)," International conference on theory and application of modeling and simulation in electrical power engineering including electric Machines, power electronic converters and power systems (Electrimacs), Québec, Canada, 8-11 June 2008.

[56] M. Turki, J. Belhadj, and X. Roboam, "Control strategy of an autonomous desalination unit fed by PV-wind hybrid system without batter storage,” Journal of Electrical Systems, vol. 4, no. 2, June 2008.

[57] W. Khiari, M. Turki, and J. Belhadj, "Power control strategy for PV/Wind reverse osmosis desalination without battery", Control Engineering Practice, vol.89, pp. 169-179, August, 2019. https://doi.org/10.1016/j.conengprac.2019.05.020. 